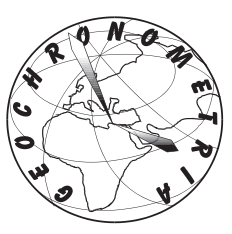

\title{
ESTABLISHING A COMMON STANDARDISED GROWTH CURVE FOR SINGLE-ALIQUOT OSL DATING OF QUARTZ FROM SEDIMENTS IN THE JILANTAI AREA OF NORTH CHINA
}

\author{
ZHENJUN LI ${ }^{1}$, XUESONG MOU ${ }^{1}$, YUXIN FAN ${ }^{1 *}$, QINGSONG ZHANG ${ }^{1}$, GUANGLIANG YANG ${ }^{1}$, HUI ZHAO $^{2}$ \\ ${ }^{1}$ Key Laboratory of Mineral Resources in Western China (Gansu Province), School of Earth Sciences, \\ Lanzhou University, China \\ ${ }^{2}$ North-west Institute of Eco-Environment and Resources, Chinese Academy of Science, Lanzhou 730000, China
}

Received 26 October $2019 \quad$ Accepted 28 August 2020

\begin{abstract}
Establishing a common standardised growth curve (SGC) can substantially reduce the instrumental time for equivalent-dose $\left(D_{e}\right)$ measurements in optically stimulated luminescence (OSL) dating. Several studies have indicated that different samples have different dose-response curves (DRCs) and therefore that it is difficult to construct a common SGC, although an SGC has been proposed in some cases. In this study, our aims were to construct a regional SGC based on small aliquots of sedimentary quartz from more than 100 samples from different sedimentary environments in the Jilantai Basin in North China and to investigate the applicability of different methods of establishing an SGC for the area. The precision of the $D_{e}$ values of aliquots which were obtained using the SGC was compared with those obtained using the single-aliquot regenerative (SAR) protocol. Our results indicate the following: (1) for establishing an SGC using the regenerative normalisation (Re-SGC) method, selecting a suitable re-normalisation dose that is close to double the characteristic saturation dose, $2 \mathrm{D}_{0}$, can reduce the inter-aliquot/inter-sample variation in the form of DRCs within a larger dose range. (2) A common regional SGC can be established for the Jilantai area using the Re-SGC and least-squares normalisation (LS-SGC) methods, which provides reliable dating results within the $200 \mathrm{~Gy} \mathrm{D}_{\mathrm{e}}$ range.
\end{abstract}

\section{Keywords}

Standardised growth curve (SGC), quartz, small aliquot, Jilantai Basin.

\section{Introduction}

In optically stimulated luminescence (OSL) dating, the burial age of sediments can be estimated by dividing the equivalent dose $\left(D_{e}\right)$ by the environmental dose rate $(D)$. OSL dating plays a key role in providing chronological frameworks in Quaternary geology, environmental archaeology and studies of paleo-earthquakes and tectonic movements. The single-aliquot regenerative-dose (SAR) procedure for quartz is widely used in measuring the equivalent dose $\left(D_{e}\right)$ of sediments (Banerjee et al., 2001), but it is time-consuming, especially for measuring old samples with high $\mathrm{D}_{\mathrm{e}}$ values. The establishment of a standardised growth curve (SGC) has the potential to substantially reduce the instrumental time required for OSL dating (Roberts and Duller, 2004). However, the applicability of the SGC method remains controversial, because several studies have suggested that different samples have different dose-response curves (DRCs), and, thus it is difficult to establish a common SGC (Murray and Wintle, 1999a, b; Chen et al., 2001; Stevens et al., 2007; Telfer et al., 2008; Chen et al., 2013). Nevertheless, the SGC method has been widely applied in dating sediments (especially loess) in several regions (Roberts and Duller, 2004; Lai, 2006, 2010; Lai et al., 2007; Long et al., 2010; Yang et al., 2011).

Corresponding author: Yuxin Fan

e-mail: yxfan@Izu.edu.cn

ISSN 1897-1695 (online), 1733-8387 (print)

(C) 2020 D. Yuxin Fan et al., This work is licensed under the Creative Commons Attribution-NonCommercial-NoDerivatives 3.0 License. 
In order to reduce inter-aliquot/inter-sample variation in the form of DRCs, a variety of methods have been developed, including the following: 1) establishing a common growth curve based on the arithmetical average value of the sensitivity-corrected OSL signal $\left(\mathrm{L}_{\mathrm{x}} / \mathrm{T}_{\mathrm{x}}\right)$ for different regenerative doses of six or more aliquots for each sample and then obtaining the $\mathrm{D}_{\mathrm{e}}$ values of additional aliquots by projecting the test-dose-corrected OSL signal on the constructed common growth curve, namely the SAR-SGC method (Lai and Ou 2013). 2) Re-normalisation of the sensitivity-corrected natural signal $\left(\mathrm{L}_{\mathrm{n}} / \mathrm{T}_{\mathrm{n}}\right)$ and regenerative-dose signal $\left(\mathrm{L}_{x} / \mathrm{T}_{\mathrm{x}}\right)$, respectively, with the OSL signals of a specific regenerative dose $(\operatorname{Lr} / \mathrm{Tr})$, which is called the regenerative normalisation or re-normalisation (Re-SGC) method (Li et al., 2015). 3) All of the regenerative-dose signals are considered for normalisation in the establishment of an SGC using a least-squares procedure, as part of an iterative scaling and fitting process, termed the LS-SGC method (Li et al., 2016).

The present study aims to investigate the applicability of the SGC method for the single-aliquot OSL dating of quartz and to establish a potential SGC of quartz fractions from sediments in different sedimentary environments (including lacustrine, fluvial and desert) in the Jilantai Basin in North China, using the three methods mentioned above. The $\mathrm{D}_{\mathrm{e}}$ values obtained using different methods are validated based on a comparison with those obtained using the SAR protocol.

\section{Study area and samples}

The Jilantai Basin is located on the western edge of the East Asian summer monsoon, in the arid-semi-arid transition zone, which is sensitive to climatic and environmental changes. The Yellow River flows through the south-eastern margin of the basin. Previous studies documented a series of ancient lake-shorelines distributed on the west bank of the Jilantai Salt Lake through remote sensing images and field investigations. It is believed that the area once contained the 'Jilantai-Hetao' megalake, which covered the entire Jilantai Basin and the adjacent Hetao Basin (Chen et al., 2008) as a result of the inflow of the Yellow River (Fan et al., 2010a). Today, most of the area of the Jilantai Basin is occupied by the Ulan Buh Desert, and only the Jilantai Salt Lake and several sporadic, small salt lakes are preserved in the western part of the area. Fluvial sediments of seasonal rivers and lacustrine sediments are preserved in the forefront of the Helan Mountains and in the north-eastern part of the Jilantai Basin. In recent years, several studies of lake-desert evolution have been carried out in the area, based mainly on OSL dating (e.g. Chen et al., 2008, 2014; Fan et al., 2010b, 2015, 2017; Zhao et al., 2012; Jia et al., 2015). The area is therefore well suited for assess- ing whether a potential SGC can be established which is suitable for samples from different profiles or sedimentary environments within a single area.

More than 100 quartz samples were used in this study, including lacustrine sediments from 16 profiles, fluvial sediments from 6 profiles and desert sediments from 6 profiles (see Figs. S1-S4 in the supplementary material for details). The location of those profiles is shown in Fig. 1a.

\section{Methods}

Quartz fractions were extracted using conventional separation methods (Fan et al., 2010b). The OSL signals from the extracted quartz fractions were measured using a Ris $\varnothing$ TL/OSL DA-20 Reader equipped with blue LEDs, infrared (IR) LEDs and an accurately calibrated ${ }^{90} \mathrm{Sr} /{ }^{90} \mathrm{Y}$ beta source, in the Key Laboratory of Western China's Environmental Systems (Ministry of Education, P.R. China) at Lanzhou University. The purity of the quartz was assessed based on the absence of an infrared-stimulated luminescence signal (IRSL) at a temperature of $50^{\circ} \mathrm{C}$ prior to measurement of the blue-stimulated luminescence signal. The natural OSL signals and regenerative-dose OSL signals were measured for quartz fractions, which were mounted on 2-mm-diameter small aliquots, using the double SAR procedure (post-IR OSL) (Banerjee et al., 2001) (Table S1). In order to select a suitable preheat temperature, a dose recovery test was performed for each sample. For these aliquots, the natural OSL signals were reset under strong sunlight in Lanzhou $\left(36.04^{\circ} \mathrm{N}, 103.8^{\circ} \mathrm{E}\right)$ for more than $6 \mathrm{~h}$, and they were then given a known laboratory dose and the recovered OSL signals measured using the protocol listed in Table S1, with a preheat temperature increasing from 160 to $260^{\circ} \mathrm{C}$ at $20^{\circ} \mathrm{C}$ intervals. Only the preheat temperature at which both the recycling ratios and dose recovery ratios (given dose/measured dose) were within the range of $0.9-1.1$, and recuperations were $<5 \%$, was employed in the protocol to measure the OSL signals. For example, a preheat temperature of $220^{\circ} \mathrm{C}$ and cut-heat temperature of $160^{\circ} \mathrm{C}$ were found to be appropriate for equivalent dose measurements of sample S63-2 (Fig. S5 and Table S2 in the supplementary materials). Detailed information on the samples is summarised in Table S2, including geographical locations, depositional environments and the grain size and conditions for measurement of the OSL signals.

The SGC was established using the sensitivity-corrected signal from a wide range of different regenerative doses using the three previously reported methods: SAR-SGC (Lai and Ou, 2013), Re-SGC (Li et al., 2015) and LS-SGC [Li et al., 2016; Peng and Li, 2017). Most of the previous researches have only validated the reliability of aliquots in which OSL signals were involved in establishing the SGC. 


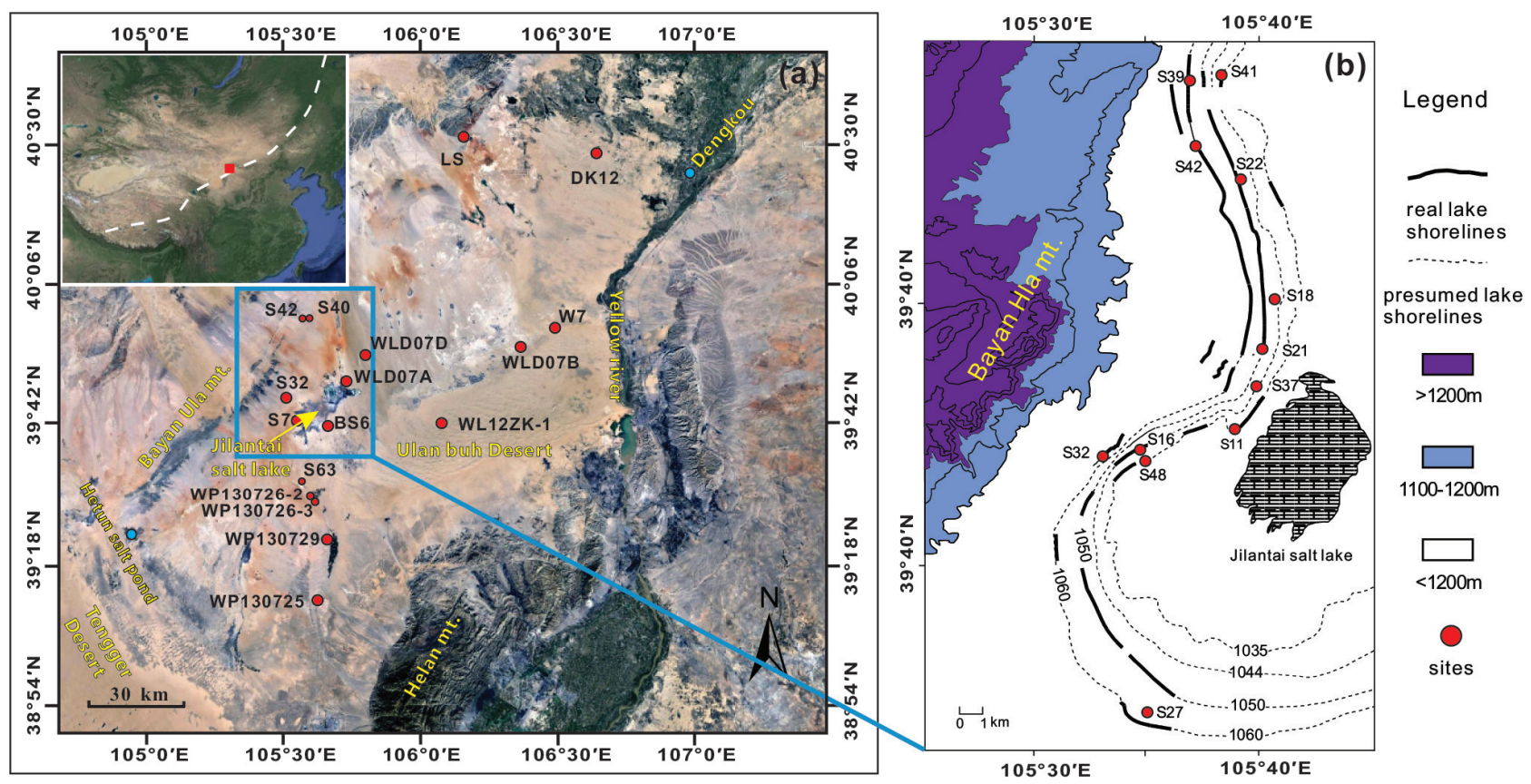

Fig 1. Regional setting (a) and sampling sites (b) (modified from Chen et al., 2008). The inset in the left upper corner of (a) is a remote sensing image of East Asia showing the location of the study area (marked by square) and the modern monsoon limit.

However, in this study, in order to investigate whether the constructed SGC is widely applicable to samples from the study area, we classified all of the aliquots into two groups: the OSL signals of aliquots with $\mathrm{D}_{\mathrm{e}}$ values widely distributed in samples of one group were used to establish the $\mathrm{SGC}$, and the OSL signals of aliquots with $\mathrm{D}_{\mathrm{e}}$ values within the range of $200 \mathrm{~Gy}$ in another group were used to validate the constructed SGC.

\subsection{SAR-SGC}

The SAR-SGC method is designed to obtain $\mathrm{D}_{\mathrm{e}}$ values from large numbers of aliquots from a single sample, assuming that aliquots of the same sample have similar DRCs. The SGC is constructed by fitting the averaged sensitivity-corrected signals $\left(L_{x} / T_{x}\right)$ of aliquots with regenerative doses in a single sample. An exponential plus linear function is usually used in curve fitting, and the $\mathrm{D}_{\mathrm{e}}$ values are obtained from the intercept value on the regenerative-dose axis (x-axis) after projecting the sensitivity-corrected natural signal $\left(\mathrm{L}_{\mathrm{n}} / \mathrm{T}_{\mathrm{n}}\right)$ to the $\mathrm{SGC}$. The formula used is as follows:

$$
y=\mathrm{a}\left[1-\exp \left(-\mathrm{x} / \mathrm{D}_{0}\right)\right]+\mathrm{cx}+\mathrm{d}
$$

Here, $y$ is the intensity of the luminescence signal; $x$ is the regenerative dose; $a$ is the normalised OSL intensity at the saturation level for the exponential growth part; $\mathrm{D}_{0}$ is the characteristic dose where the slope of the growth curve (the exponential part) is equal to $1 / e$ of the initial value; $\mathrm{c}$ is a constant defining the slope of the linear part of the growth curve; and $d$ is the intensity of the luminescence signal at 0 Gy (Lai et al., 2007; Lai and Ou, 2013).

For the establishment of an SGC appropriate for samples from within a study profile, curve fitting was performed based on the DRCs of all samples from that profile, after excluding the DRC of the few outliers $(<20 \%)$ having dose-response curves which are markedly different from those of the majority of the aliquots for that sample.

\subsection{Re-SGC}

Roberts and Duller (2004) suggested that inter-aliquot variation can be normalised using OSL signals of the test dose $\left(\mathrm{D}_{\mathrm{t}}\right)$ in order to produce a 'standardised luminescence signal' $\left(\left(\mathrm{L}_{\mathrm{x}} / \mathrm{T}_{\mathrm{x}}\right) * \mathrm{D}_{\mathrm{t}}\right)$. However, the similarity of the shape of a DRC of a test-dose-corrected signal $\left[\left(\mathrm{L}_{\mathrm{x}} /\right.\right.$ $\left.\mathrm{T}_{\mathrm{x}}\right) * \mathrm{D}_{\mathrm{t}}$ ] for different aliquots and grains depends critically on changes in the inter-aliquot and inter-grain sensitivity $(k)$ between the natural or regenerative-dose step and the test-dose measurement, especially at low doses; and it also depends on variations in both $k$ and the characteristic dose values $\left(\mathrm{D}_{0}\right)$ at higher doses (Li et al., 2015). In order to reduce the effect of inter-aliquot/inter-grain variation in $k$ for normalising the DRCs of single aliquots, an improved normalisation procedure using the OSL signal of an extra regenerative dose, called the Re-SGC method, was proposed ( $\mathrm{Li}$ et al., 2015). Compared to the sensitivity-corrected OSL signal $\left(\mathrm{L}_{x} / \mathrm{T}_{x}\right)$, the measurement of the 
OSL signal of an extra regenerative dose is required in the Re-SGC method (Peng et al., 2016). In detail, in the ReSGC method, the sensitivity-corrected natural signal ( $\mathrm{L}_{\mathrm{n}}$ ! $\left.\mathrm{T}_{\mathrm{n}}\right)$ and regenerative-dose signal $\left(\mathrm{L}_{\mathrm{x}} / \mathrm{T}_{\mathrm{x}}\right)$ are re-normalised by dividing by the OSL signal $\left(\mathrm{L}_{\mathrm{r} 1} / \mathrm{T}_{\mathrm{r} 1}\right)$ of the extra specific regenerative dose $\left(\mathrm{D}_{\mathrm{r} 1}\right)$ (Li et al., 2015). In addition, the exponential plus linear function is usually involved in fitting the re-normalised signals to establish the SGC.

\subsection{LS-SGC}

In order to further reduce the variation in the test-dosecorrected signals, Roberts and Duller (2004) and Li et al., (2016) proposed a new normalisation method similar to the re-normalisation method of $\mathrm{Li}$ et al., (2015), termed 'least-squares normalisation' (LS-normalisation). Here, compared to the re-normalisation method, all regenerative-dose signals are considered for normalisation with the least-squares procedure involved in the iterative scaling and fitting procedure. Importantly, this normalisation method does not change the form of the DRCs for individual aliquots, and it only shifts all of the signal points of each aliquot upwards and downwards along the y-axis at the same ratio. In so doing, it minimises the difference between the DRCs of each aliquot.

The LS-SGC method involves a multiple iterative scaling and fitting process. The R package num OSL (version 2.5), written by Peng and Li (2017), implements the calculation of a series of iterative scaling and fitting processes required in the method. In this study, after extraction of the OSL signals of aliquots from Analyst (version 4.31), the subsequent iterative calculation was performed using part of the code in the R package num OSL (Peng and Li, 2017). The detailed steps are as follows:

1) Fitting the test-dose-corrected regenerative-dose OSL signals $\left(\mathrm{L}_{\mathrm{x}} / \mathrm{T}_{\mathrm{x}} * \mathrm{D}_{\mathrm{e}}\right)$ using the GOK (generalorder kinetic model) function. The choice of the fitting function for 'starting curves' is not crucial and does not affect the final results after iteration, which are only related to the number of iterations ( $\mathrm{Li}$ et al., 2016). Thus, a more flexible GOK function (Guralnik et al., 2015) is used in fitting because the GOK function can automatically change its shape according to changes in the data during the fitting process, which greatly reduces the problems caused by function selection in the fitting.

2) The test-dose-corrected regenerative-dose OSL signals of each aliquot are multiplied by a scaling factor, such that the sum of the squared residuals (the difference between the test-dose-corrected regenerative-dose OSL signal values, multiplied by the scaling factor and the fitted y value in step 1) is minimised. Note that the scaling factor could be different for different aliquots.
3) The normalised experimental data obtained for each aliquot in step 2 are then fitted again using one of the followings: single saturation exponential function (EXP), double saturation exponential function (DEXP), and single saturation exponential plus linear function (LEXP). (The function does not have to be the same as the initial fitting function in step 1.) The best fitting function is determined using a chi-square test.

4) Iteratively repeat steps 2 and 3 , and the re-scaled data set in step 2 for each aliquot are then multiplied by a new scaling factor in order to minimise the least-squared residuals with the newly fitted DRC in step 3. The newly re-scaled data are then fitted again using the best-fit functions determined by chisquared tests. For all growth curves, steps 2 and 3 are iteratively repeated until the change in all of the normalised data and the fitted SGC curve is $<1 \%$. The best-fit curve is considered as the SGC.

The code is as follows:

\#load program

library(numOSL)

\#establish SGC

data<-read.csv("DK12.csv")

res_1sNORM $<-1$ sNORM(data, model="go

k", origin=FALSE, weight=TRUE, natural. $\mathrm{rm}=$ TRUE, maxiter $=10$ )

\#calculating the $\mathrm{D}_{\mathrm{e}}$ obtained by SGC

data1<-read.csv("DK12.csv")

res < - calsGCED(as_analyseBIN(data 1$)$, SGCpars=res_lsNORM\$LMpars2[,1],model="go k",method="gSGC",origin=FALSE, avgDev=res _ 1sNORM\$avg.error2,errMethod="sp",SAR.Cycle= c(“N","R2"), outpdf="DK12SGCED",outfile="DK1 2SGCED")

\section{Results}

\subsection{Choice of re-normalisation dose in the Re-SGC method}

The essence of the Re-SGC method is to take the signal of a specific regenerative dose as a reference point (hereafter called the re-normalisation dose), with which the DRCs of all samples are normalised in order to establish a common DRC suitable for samples from the same profile or even from different regions. In addition, via numerical simulations, the degree of reduction of the variation of the inter-aliquot/inter-sample ratio is observed to be slightly different when different regenerative doses were used for re-normalisation of the growth curves [Peng et al., 2016]. Until now, however, there is no uniform definition of the re-normalisation dose. For example, Li et al., (2015) selected the re-normalisation dose of $172 \mathrm{~Gy}$ in the establishment of a global standard growth curve ( $\mathrm{gSGC}$ ) with the function $y=0.787[1-\exp (-x / 73.9)]+0.001539 x+0.01791$, based 
on quartz samples from different regions worldwide, using the Re-SGC method. In addition, Hu et al., (2016) selected $48 \mathrm{~Gy}$ as the re-normalisation dose to establish the SGC with the function $\mathrm{y}=3.7639\{1-\exp [-(x+2.1486) / 164.377]\}$ for quartz grains in glacial deposits from the Qilian Mountains; and Yang et al., (2017) selected 80 Gy as the re-normalisation dose in establishing the SGC with the function $y=1.09262[1-\exp (-x / 64.6292)]+0.00276 x+0.01062$ for quartz grains from sediments of the Badain Jaran Desert.

In order to select a suitable re-normalisation dose for re-normalisation of the sensitivity-corrected natural signal $\left(\mathrm{L}_{\mathrm{n}} / \mathrm{T}_{\mathrm{n}}\right)$ and regenerative-dose signal $\left(\mathrm{L}_{\mathrm{x}} / \mathrm{T}_{\mathrm{x}}\right)$, we compared the impact on the relative standard deviation (RSD) and dispersion of the sensitivity-corrected OSL signals caused by different re-normalisation doses for representative sample LS-4 (Fig. 2) and from all of the samples in the area (Fig. 3). In detail, the comparison of the RSD and the dispersion of the re-normalisation of sensitivity-corrected OSL signals by re-normalisation doses of $73,146,220,293$, and 440 Gy for representative sample LS-4 indicates that the RSD (Fig. 2a) and the dispersion of the re-normalised signals of aliquots (Fig. 2b) were reduced, especially for doses within the regenerative-dose range of 73-300 Gy, when renormalised with doses of 146 and $220 \mathrm{~Gy}$.

For all samples in the study area, the comparison made with re-normalisation using re-normalisation doses of $88 \mathrm{~Gy}$, 147 Gy and 220 Gy (Fig. 3) shows that re-normalisation of sensitivity-corrected OSL signals of aliquots with a re-normalisation dose of $147 \mathrm{~Gy}$ yielded the smallest dispersion of the re-normalised OSL signals, which corresponds to a regenerative dose up to 250 Gy (Fig. 3b). As the characteristic saturation dose $\left(\mathrm{D}_{0}\right)$ of quartz in most samples in this area is $\sim 75$
Gy, the comparison made in this study therefore shows that when using the Re-SGC method in quartz, re-normalisation of the sensitivity-corrected OSL signals $\left(\mathrm{L}_{\mathrm{x}} / \mathrm{T}_{\mathrm{x}}\right)$ using an extra renormalisation dose close to two times of the characteristic saturation dose $\left(2 \mathrm{D}_{0}\right)$ enables a value of $\mathrm{D}_{\mathrm{e}}$ to be easily obtained, which has a smaller RSD of the re-normalisation OSL signals within the wide range of $0-200 \mathrm{~Gy}$.

\subsection{The SGC of a single profile}

In this study, the SGC is established for each profile using the SAR-SGC, Re-SGC and LS-SGC methods. The results for representative profile LS and the other profiles are illustrated in Fig. 4 and supplementary Figs. S6-S14, respectively.

It is evident that the response of the sensitivity-corrected OSL signals $\left(L_{x} / T_{x}\right)$ to the regenerative dose for samples from the profile is dispersed (Fig. 4a). Moreover, using the SARSGC method, the DRC would only be established for sensitivity-corrected OSL signals $\left(\mathrm{L}_{x} / \mathrm{T}_{\mathrm{x}}\right)$ of aliquots in a single sample after elimination of aliquots with substantial deviations. However, within the same profile, the DRCs established for different samples deviate substantially from each other (Fig. 4b), and it is difficult to determine a common growth curve that is suitable for samples from the same profile, with an acceptable degree of accuracy, using the SAR-SGC method.

Relative to the sensitivity-corrected OSL signal (Fig. 4a), based on the Re-SGC method, all of the sensitivity-corrected OSL signals $\left(\mathrm{L}_{x} / \mathrm{T}_{\mathrm{x}}\right)$ were re-normalised by dividing the OSL response $\left(\mathrm{L}_{147} / \mathrm{T}_{147}\right)$ of the extra re-normalisation dose by $147 \mathrm{~Gy}$, which is close to the $2 \mathrm{D}_{0}$ value. Therefore, the deviation of the re-normalised OSL signals among aliquots is reduced and a common SGC can be more reasonably established, especially within the dose range of
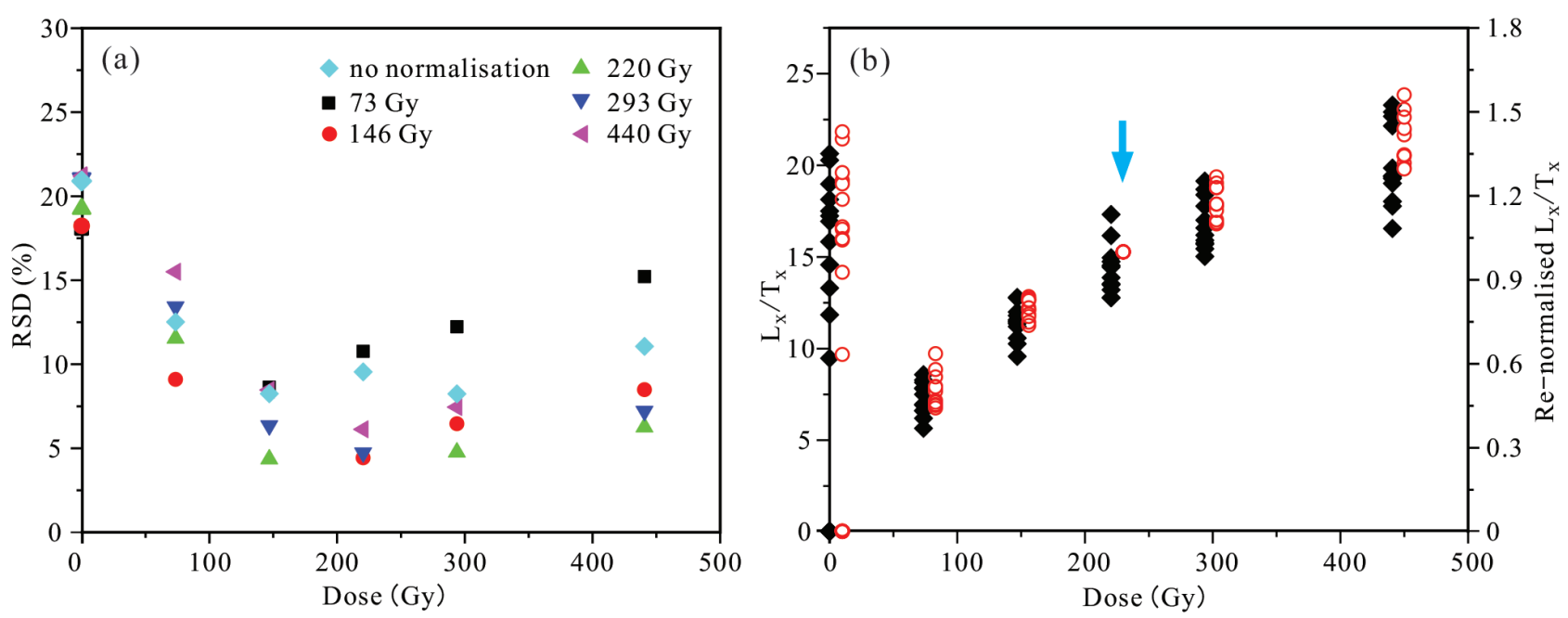

Fig 2. (a) Relative standard deviation (RSD) of the sensitivity-corrected natural signal $\left(L_{n} / T_{n}\right)$ and re-normalised regenerative-dose signals ( $\left.L_{\gamma} / T_{x}\right)$ of representative sample LS-4 (the diamond symbol), plotted versus the regenerative doses. (b) Plots of the sensitivity-corrected natural signal ( $\left.L / T T^{\prime}\right)$ and regenerative dose signal (L/T) (filled black diamonds) (left-hand axis) versus the regenerative dose, and plots of the re-normalised signals with the extra regenerative dose of $220 \mathrm{~Gy}$ (red circles) which are plotted using an offset of a few Gy offset to the right on the x-axis for clarity (right-hand axis). 

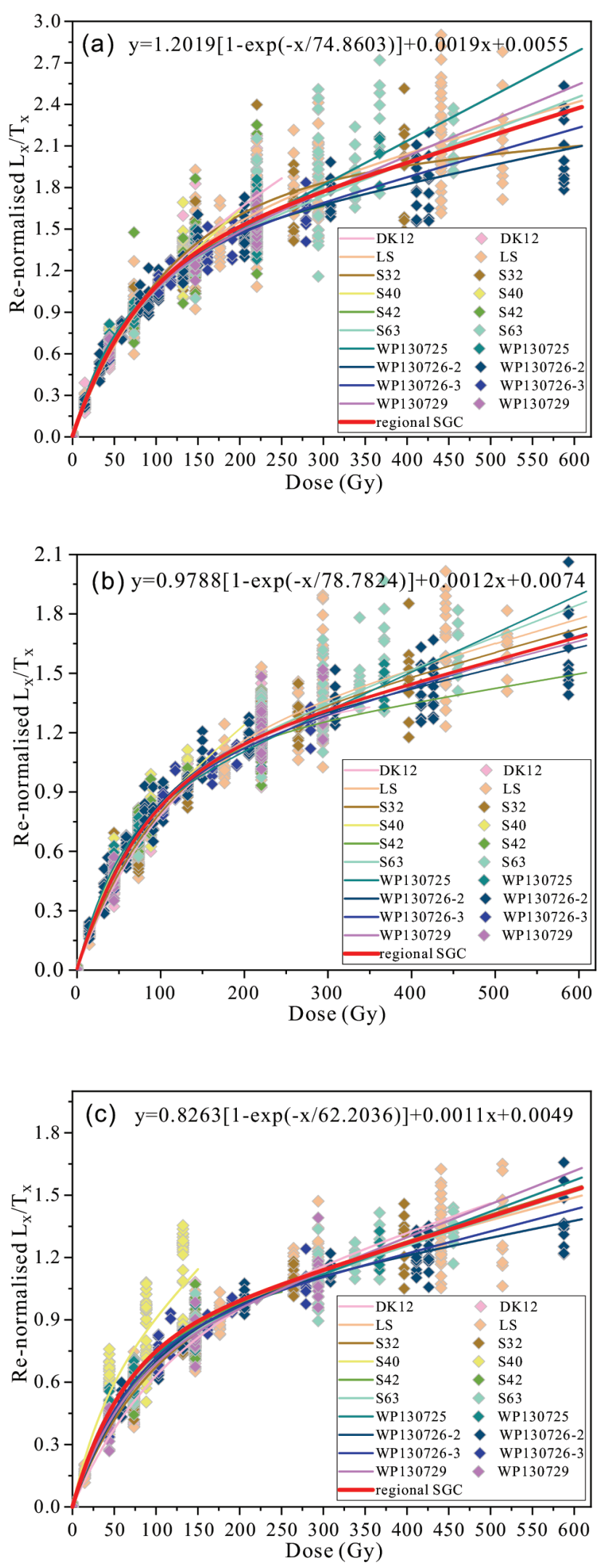

Fig 3. Comparison of the re-normalisation results with OSL signals of the re-normalisation dose of (a) $88 \mathrm{~Gy}$, (b) $147 \mathrm{~Gy}$ and (c) $220 \mathrm{~Gy}$.
$200 \mathrm{~Gy}$, although the re-normalised signals are dispersed when $\mathrm{D}_{\mathrm{e}}>200 \mathrm{~Gy}$ (Fig. 4c).

When the LS-SGC method is used, the variation in the test-dose-corrected OSL signals $\left(\mathrm{L}_{\mathrm{x}} / \mathrm{T}_{\mathrm{x}} * \mathrm{D}_{\mathrm{t}}\right)$ with the regenerative dose was fitted using a flexible function, and therefore, almost the same calibration level was reached among the regenerative doses for aliquots within the entire dose range. This does not alter the shape of the DRC of each aliquot, and it only minimises the difference between the DRCs of each aliquot. Almost the same dispersion range was obtained up to $300 \mathrm{~Gy}$, and even up to $500 \mathrm{~Gy}$, and therefore, a common DRC could be obtained for the samples from this profile (the red line in Fig. 4d).

In summary, a comparison based on samples from the same profile indicates the following. 1) The difference between sensitivity-corrected signals among samples was not substantially reduced using the SAR-SGC method, and therefore, it is difficult to establish a suitable SGC for the samples from a profile. 2) Using the Re-SGC method, differences in the sensitivity-corrected OSL signals among samples and aliquots can be effectively reduced when they are re-normalised with the OSL signal response to the extra re-normalisation dose, which is close to double the characteristic saturation dose $\left(2 \mathrm{D}_{0}\right)$. Therefore, an SGC suitable for samples from the same profile can be established with maximum $\mathrm{D}_{\mathrm{e}}$ values up to $200 \mathrm{~Gy}$. 3) Using the LS-SGC method, without considering any additional re-normalisation dose, the differences in the sensitivity-corrected signals among samples and aliquots from the same profile were uniformly reduced with a regenerative dose up to 300-500 Gy. Therefore, it is possible to establish an SGC suitable for samples from the entire area within a wide dose range using either the Re-SGC or LS-SGC method.

\subsection{Regional SGC for the Jilantai area}

By using the Re-SGC and LS-SGC methods, the difference in the re-normalised OSL signals among samples and aliquots can be effectively reduced, and therefore, we tried to establish a potential SGC that is suitable for the quartz fraction of sediments from the entire Jilantai region (hereafter termed the regional SGC). Based on the OSL signals of the quartz fraction in samples from different profiles within the entire Jilantai Basin, the regional SGCs were established with the fitting results illustrated in Fig. 5 (red lines). The function of the regional SGC obtained using the Re-SGC method is given below:

$$
y=0.9788[1-\exp (-x / 78.78235)]+0.00116 x+0.00737
$$

and the function of the regional SGC obtained by the LSSGC method using the GOK function is as follows:

$$
y=195\left[1-(1+0.0039 \times 3.6 \times x)^{\wedge}(-1 / 3.6)\right]+0.0509
$$



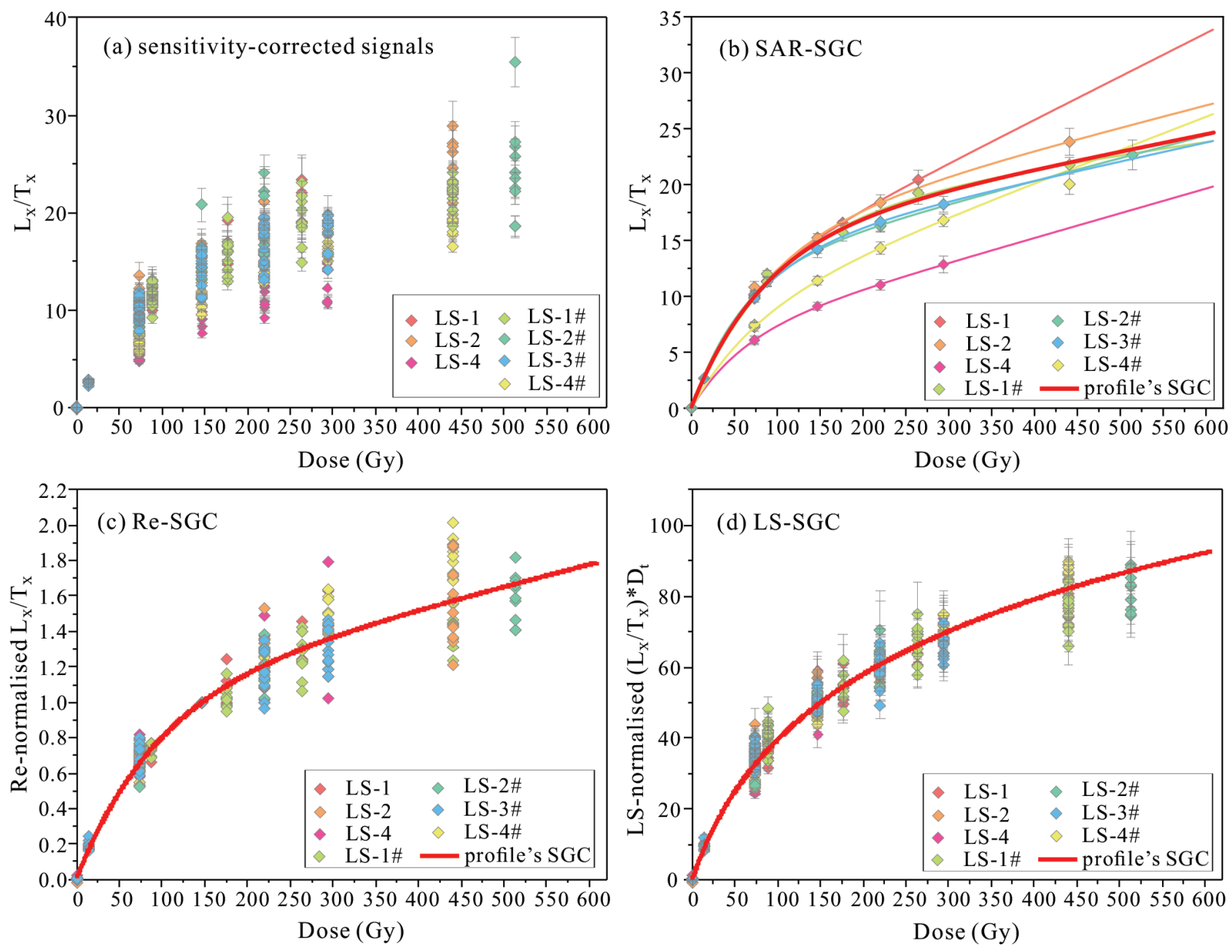

Fig 4. Comparison of re-normalised OSL signals $(b, c$ and $d)$ with the sensitivity-corrected OSL signals (a) from samples from the LS profile. IIIustration of the potential SGCs established using (b) SAR-SGC, (c) Re-SGC and (d) LS-SGC methods. The diamonds represent the OSL signals of different samples, and the red curve represents the fitted SGC. In (b), the potential SGCs of different profiles are shown using the same colour as in the legend in Fig. 4-4b.

In order to assess the quality of the SGCs, we calculated the ratios between the re-normalised $\mathrm{L}_{\mathrm{x}} / \mathrm{T}_{\mathrm{x}}$ data (or LSnormalised $\mathrm{L}_{x} / \mathrm{T}_{x}$ data) and the corresponding value on the SGC at the same dose and plotted them as a function of dose in Fig. 5c and d. Similarly, we plotted the ratios of $\mathrm{D}_{\mathrm{e}}$ measured through normalised $\mathrm{L}_{x} / \mathrm{T}_{x}$ data and that obtained from the SGC in a radial plot in Fig. 5e and f. There is no systematic dose dependency of the ratios for these two SGC methods, which is consistent with the observations on K-feldspar SGC (Li et al., 2018). In the radial plots in Fig. 5e and f, $85 \%$ and $90 \%$ of the total have ratios close to unity within $2 \sigma$ range for the Re-SGC and LS-SGC methods, respectively, which closely matches statistical expectations (95\%). These results imply the existence of a common regional SGC that can be established for the Jilantai area using the Re-SGC and LS-SGC methods.
Comparison of the re-normalised OSL signals, the fitting curves of samples from different profiles and the regional SGC (Fig. 5a and b) indicates the following. (1) Within the dose range of 0-200 Gy, the deviation in the shape of the fitting curves of samples from different profiles is less dispersed; therefore, a regional SGC can be established using either the Re-SGC or LS-SGC method. (2) Using the Re-SGC method, the regional SGC established from samples from different profiles shows deviations from the SGCs obtained from different profiles for regenerative doses $>200 \mathrm{~Gy}$, which may be due to scattered re-normalised signals. (3) Relative to the re-normalised OSL signals obtained using the Re-SGC method, the re-normalised OSL signals obtained by the LS-SGC method are substantially less dispersed, and the regional SGC established from the LS-SGC method is almost 

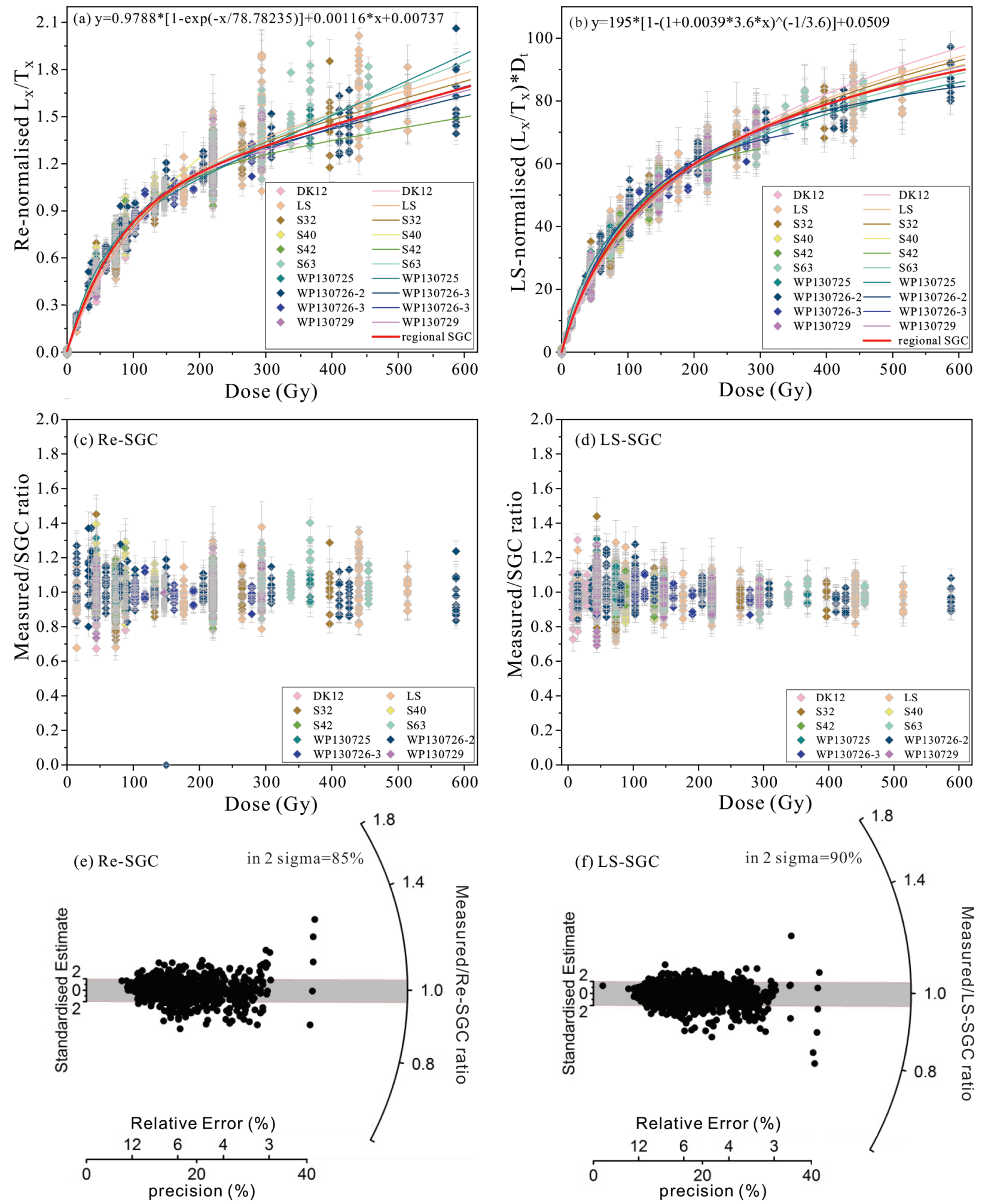

Fig 5. (a) The regional SGC (red curve) and DRCS from samples of profiles (the other coloured curves) established using the Re-SGC method. (b) The regional SGC (red curve) and DRCS of profiles (the other coloured curves) established using the LS-SGC method. (c) Ratios between the re-normalised data and the Re-SGC in (a), plotted against regenerative dose. (d) Ratios between the LS-normalised data and the LS-SGC in (b), plotted against regenerative dose. (e) Radial plot of the ratios shown in (c). (f) Radial plot of the ratios shown in (d). In the plots (e) and (f), the relatively high precision of 5-6 points, which scatter from the rest of the data points, was caused by OSL signal saturation. 
overlapped by up to 300 Gy with DRCs obtained from most of the samples from a single profile. Deviations only occur when the regenerative dose is $>300 \mathrm{~Gy}$.

\section{Discussion}

To validate the $\mathrm{D}_{\mathrm{e}}$ values obtained through the regional SGC based on the Re-SGC and LS-SGC methods, a comparison was made with the $\mathrm{D}_{e}$ values obtained using the SAR protocol. For samples for which OSL signals were involved in establishing the SGC, we calculated the $\mathrm{D}_{e}$ values of 379 aliquots from the regional SGCs established using the ReSGC and LS-SGC methods and made a comparison with the $\mathrm{D}_{\mathrm{e}}$ values obtained using the SAR protocol. From the plots of $\mathrm{D}_{\mathrm{e}}$ values obtained from the regional SGC using the ReSGC method versus those obtained using the SAR protocol
(Fig. 6a), it was found that $78 \%$ of the $\mathrm{D}_{\mathrm{e}}$ values obtained from these two methods are consistent within a $20 \%$ error range of unity, and $53 \%$ were consistent within a $10 \%$ error range of unity. If the comparison is constrained within the range of $\mathrm{D}_{\mathrm{e}}<200 \mathrm{~Gy}$, within which most of the $\mathrm{D}_{\mathrm{e}}$ values are unsaturated, then $86 \%$ of the $\mathrm{D}_{\mathrm{e}}$ values are consistent within a $20 \%$ error range of unity, and $63 \%$ are consistent within a $10 \%$ error range of unity. In a comparison of $D_{e}$ values obtained from the regional SGC established using the LS-SGC method with those obtained from the SAR protocol (Fig. 6b), $56 \%$ of the $\mathrm{D}_{\mathrm{e}}$ values are consistent within a $10 \%$ error range of unity and $81 \%$ are consistent within a $20 \%$ error range of unity. If the comparison is constrained within the range of $\mathrm{D}_{\mathrm{e}}<200 \mathrm{~Gy}, 84 \%$ of the $\mathrm{D}_{\mathrm{e}}$ values are consistent within a $20 \%$ error range of unity, and $61 \%$ are consistent within a $10 \%$ error range of the unity. For $\mathrm{D}_{\mathrm{e}}>300 \mathrm{~Gy}$, most
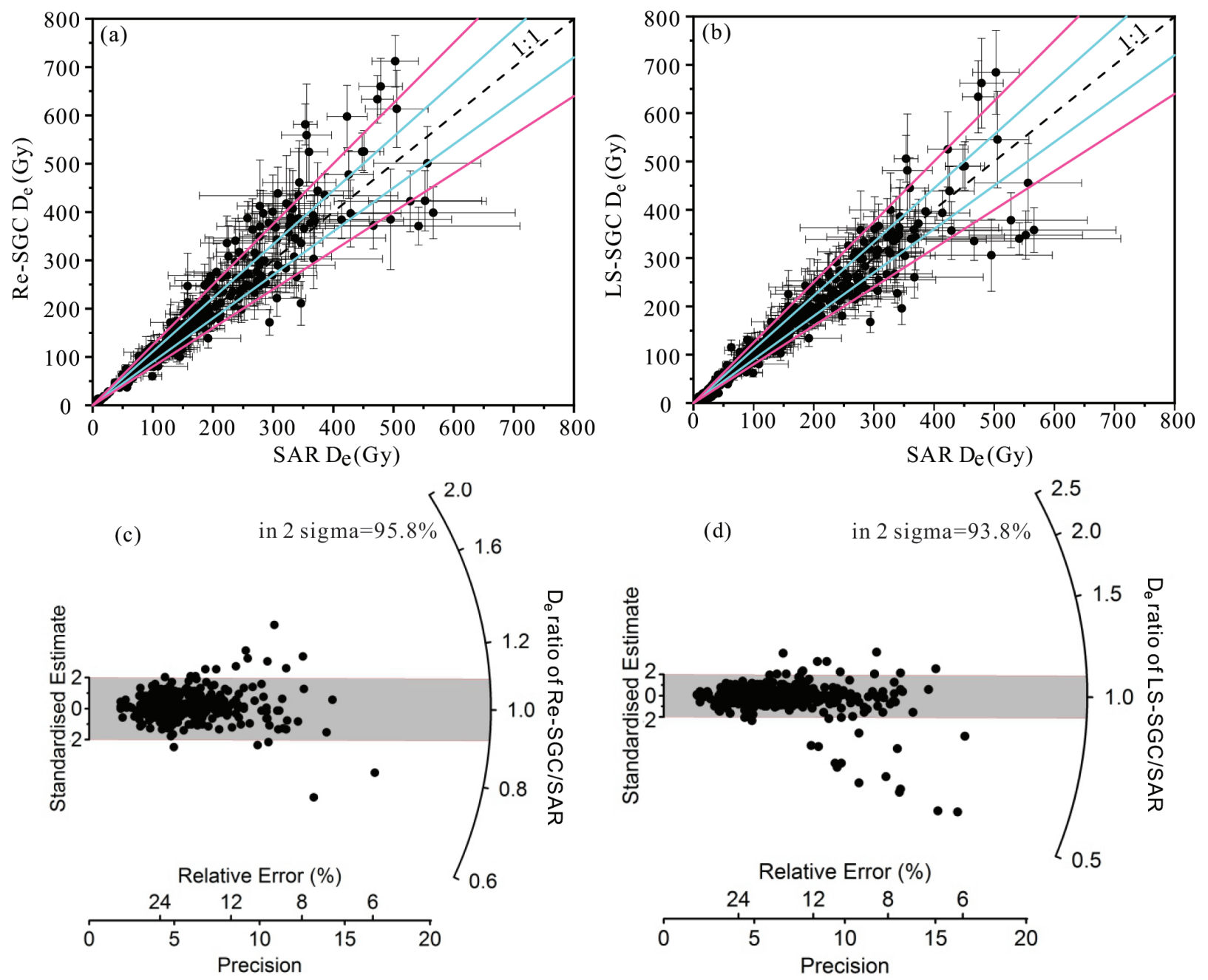

Fig 6. Comparison of $D_{e}$ values obtained using the SAR protocol with those obtained using the Re-SGC (a) and LS-SGC (b) methods. The dashed black line is the 1:1 line, the solid blue lines define the 10\% error range, and the solid pink lines define the $20 \%$ error range. (c) Radial plot showing ratios of the Re-SGC $D_{e}$ values to the SAR $D_{e^{*}}(d)$ Radial plot showing the ratios of the LS-SGC $D_{e}$ values to the SAR $D_{e^{.}}$In the plot (d), 10 points with very low ratio were caused by OSL signal saturation. 
of the data are scattered except for a small percentage which are distributed along the 1:1 line which is defined by the ratio of the $\mathrm{D}_{\mathrm{e}}$ values obtained using the Re-SGC (or LS-RGC) method with those obtained from the SAR protocol. This indicates a large discrepancy in $\mathrm{D}_{\mathrm{e}}$ values $>300$ Gy between those obtained by using the regional SGCs established either using either the Re-SGC or LS-SGC method and those obtained using the SAR protocol (Fig. 6). This phenomenon may be the result of the saturation of the OSL signals. We also calculated the ratio of $\mathrm{D}_{\mathrm{e}}$ values between those obtained from the SGCs and from the SAR protocol (Fig. 6c and d). From the $\mathrm{D}_{\mathrm{e}}$ value ratios of Re-SGC to SAR, $95.8 \%$ of aliquots have ratios close to unity within the $2 \sigma$ range (Fig. $6 \mathrm{c}$ ). For the ratios of LS-SGC to SAR $D_{e}$ values, $93.8 \%$ of ratios are close to unity within $2 \sigma$ (Fig. 6d).

In order to further investigate whether the regional SGCs established using the Re-SGC and LS-SGC methods are widely applicable to samples from the study area, an additional comparison of $D_{e}$ values $(<200 \mathrm{~Gy})$ was made on samples which were not involved in the establishment of the regional SGC. A total of 310 aliquots were used in the comparison. In general, the $\mathrm{D}_{\mathrm{e}}$ values obtained using the regional SGC were consistent with those obtained using the SAR protocol within a $20 \%$ error range of unity (Fig. 7a and b). This situation is almost the same as that for the samples involved in the establishment of the regional SGCs (Fig. 6), which indicates that the two regional SGCs established from the limited sample set are also suitable for other samples from the Jilantai Basin. In detail, within the $\mathrm{D}_{\mathrm{e}}$ range of 50-200 Gy, from the regional SGC established using the Re-SGC method, $69 \%$ of the aliquots yielded $\mathrm{D}_{\mathrm{e}}$ values consistent with those obtained using the SAR protocol within a $10 \%$ error range of the unity, and $92 \%$ were consistent within the $20 \%$ error range of unity (Fig. 7a). From the regional SGC established using the LS-SGC method, $72 \%$ of the aliquots yielded $\mathrm{D}_{\mathrm{e}}$ values consistent with those obtained using the SAR protocol within a $10 \%$ error range of unity, and $92 \%$ were consistent within the $20 \%$ error range of unity (Fig. $7 b$ ). However, for $\mathrm{D}_{\mathrm{e}}<50$ Gy, the number of aliquots with $D_{e}$ values obtained using different methods consistent with those obtained using the SAR protocol within the $10 \%$ and $20 \%$ error ranges of unity was reduced significantly (Fig. 7c and d). In addition, the Re-SGC (or LS-SGC) and SAR $\mathrm{D}_{\mathrm{e}}$ values are consistent, with more than $98 \%$ of the aliquots having ratios of SGC to SAR $D_{e}$ clustered tightly within the $2 \sigma$ range of unity (Fig. 7e and f).

In summary, irrespective of which regional SGC is established, within the $10 \%$ error range, more than $50 \%$ of aliquots have $\mathrm{D}_{\mathrm{e}}$ values consistent with those obtained using the SAR protocol, and within the $20 \%$ error range, more than $80 \%$ of aliquots have $\mathrm{D}_{\mathrm{e}}$ values consistent with those using the SAR protocol. Similarly, more than $95 \%$ of the aliquots had ratios of SGC to SAR $\mathrm{D}_{\mathrm{e}}$ consistent with unity at $2 \sigma$. Within the range of $\mathrm{D}_{\mathrm{e}}<200 \mathrm{~Gy}$, the comparison of the $\mathrm{D}_{\mathrm{e}}$ values obtained using regional SGCs established using the Re-SGC and LS-SGC methods with those obtained using the SAR protocol indicates that the $\mathrm{D}_{\mathrm{e}}$ values obtained using these two regional SGCs are consistent. Therefore, a valid SGC can be produced for the Jilantai area within the 200 Gy range.

\section{Conclusions}

Based on the OSL signals of small-aliquot quartz fractions of samples collected from different sedimentary environments in the Jilantai Basin, we have tried to establish a common SGC that is generally appropriate for samples from the area. Our main findings are as follows:

(1) The inter-aliquot difference in sensitivity-corrected OSL signals can be effectively reduced using the Re-SGC and LS-SGC methods, and therefore, it is possible to establish a common SGC using these methods. However, the SAR-SGC method is not suitable for establishing a common SGC of quartz fractions, which is suitable for different samples from a profile or a region.

(2) Using the Re-SGC method, selecting a re-normalisation dose that is close to double the characteristic saturation dose, $2 \mathrm{D}_{0}$, can reduce the variation in the shape of the DRCs among samples within a larger dose range. This is supported by a comparison in the RSD and dispersion of the renormalised OSL signals with different sizes of renormalisation dose.

(3) For $\mathrm{D}_{\mathrm{e}}<200 \mathrm{~Gy}, \mathrm{D}_{\mathrm{e}}$ obtained using the Re-SGC and LS-SGC methods is generally consistent with that obtained using the SAR protocol, which indicates that there is a common regional SGC in the Jilantai area. For the Jilantai area, the function of the regional SGC obtained by the Re-SGC method is $y=0.9788[1-\exp (-x / 78.78235)]+0.00116 x+$ 0.00737 , and the function of the regional SGC obtained by the LS-SGC method is $\mathrm{y}=195[1-(1+$ $\left.0.0039 \times 3.6 \times x)^{\wedge}(-1 / 3.6)\right]+0.0509$.

\section{Acknowledgements}

This research was jointly supported by the National Natural Science Foundation of China (awards 41772169 and 91962212), Pan-TPE (award XDA2009000001) and the Fundamental Research Funds for the Central Universities (No. Lzujbky-2018-it21). We thank Dr. Li B. for his suggestion in improving the primary manuscript and Dr. Jan Bloemendal for improving the English of the manuscript. 

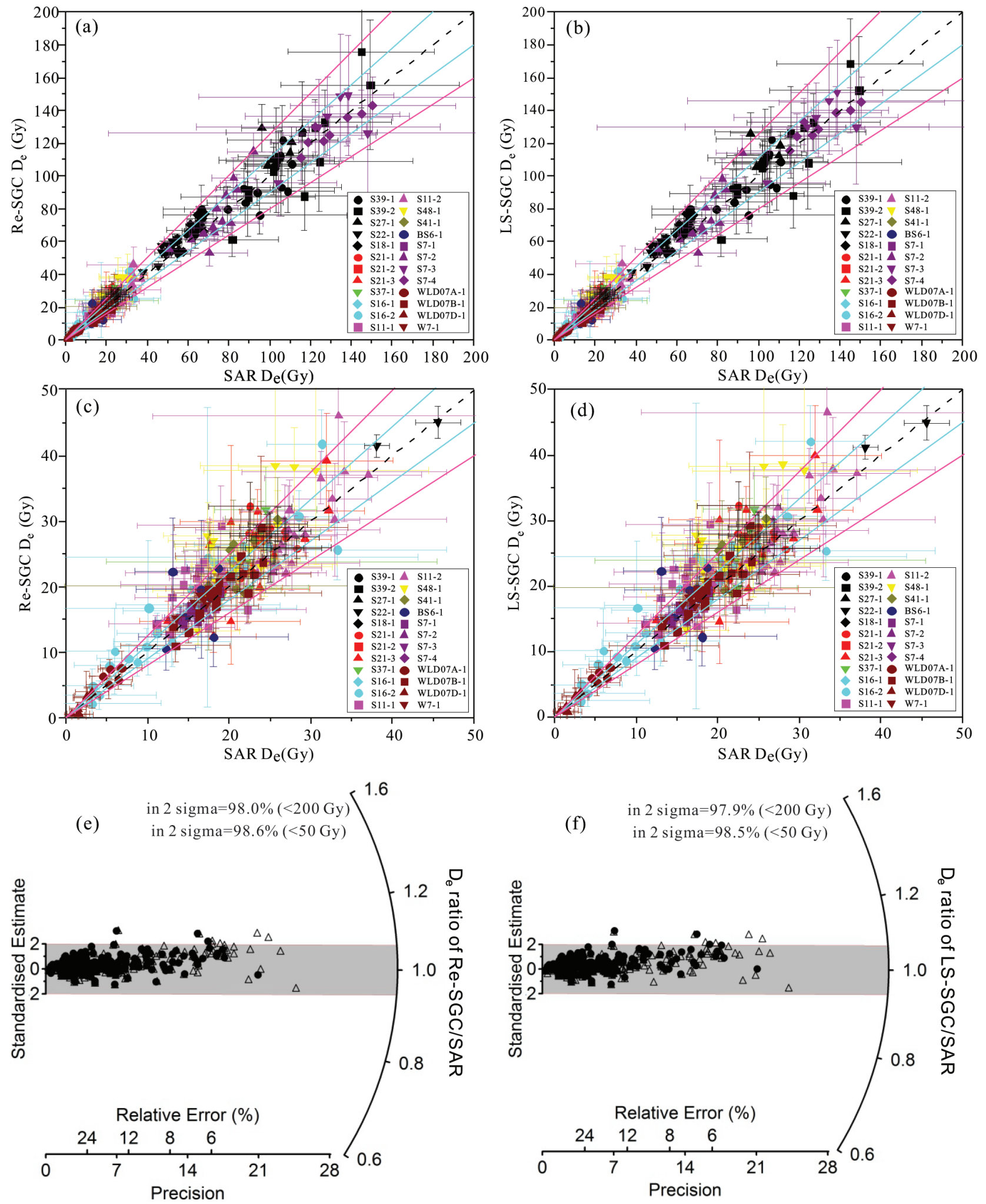

Fig 7. Comparison of $D_{e}$ values obtained using the SAR protocol with those obtained using the regional SGCS established using the Re-SGC (a and c) and LS-SGC (b and d) methods, for samples which were not used in the establishment of the regional SGCs. In these plots, the black dashed lines are the 1:1 ratio, and the areas enclosed by the blue solid lines are the 10\% error range of unity, and the areas enclosed by the pink solid lines are the $20 \%$ error range of unity. (e) Radial plot showing the ratios of the Re-SGCD values to the SAR D. (f) Radial plot showing the ratios of the LS-SGC $D_{e}$ values to the SAR $D_{e}$. Within (e) and (f), the data within $200 \mathrm{~Gy}$ are shown as open triangles and those $<50 \mathrm{~Gy}$ as filled circles. 


\section{References}

Banerjee D, Murray AS, B $\varnothing$ tter-Jensen L and Lang A, 2001. Equivalent dose estimation using a single aliquot of polymineral fine grains. Radiation Measurements 33(1): 73-94, DOI: 10.1016/ S1350-4487(00)00101-3.

Chen FH, Fan YX, Chun X, Madsen DB, Oviatt CG, Zhao H, Yang LP and Sun $Y, 2008$. Preliminary research on Megalake JilantaiHetao in the arid areas of China during the Late Quaternary. Chinese Science Bulletin 53(11): 1725-1739, DOI: 10.1007/ s11434-008-0227-3.

Chen FH, Li GQ, Zhao H, Jin M, Chen XM, Fan, YX, Liu XK, Wu D and Madsen D, 2014. Landscape evolution of the Ulan Buh Desert in northern China during the late Quaternary. Quaternary Research 81(3): 476-487, DOI: 10.1016/j.yqres.2013.08.005.

Chen G, Murray AS and Li SH, 2001. Effect of heating on the quartz dose-response curve. Radiation Measurements 33(1): 59-63, DOI: 10.1016/S1350-4487(00)00134-7.

Chen GQ, Yi L, Xu XY, Yu HJ, Cao JR, Su Q, Yang LH, Xu YH, Ge $J Y$ and Lai ZP, 2013. Testing the standardized growth curve (SGC) to OSL dating coastal sediments from the south Bohai Sea, China. Geochronometria 40(2): 101-112, DOI: 10.2478/ s13386-013-0103-z.

Fan YX, Chen FH, Wei GX, Madsen DB, Oviatt C, Zhao H, Chun $X$, Yang LP, Fan TL and Li GQ, 2010a. Potential water sources for Late Quaternary Megalake Jilantai-Hetao, China, inferred from mollusk shell ${ }^{87} \mathrm{Sr} /{ }^{86} \mathrm{Sr}$ ratios. Journal of Paleolimnology 43(3): 577-587, DOI: 10.1007/s10933-015-9876-9.

Fan YX, Chen FH, Fan TL, Zhao H and Yang LP, 2010b. Sedimentary documents and Optically Stimulated Luminescence (OSL) dating for formation of the present landform of the northern Ulan Buh Desert, northern China. Science China Earth Sciences 53(11): 1675-1682, DOI: 10.1007/s11430-010-3085-1.

Fan YX, Chen XL, Liu WH, Zhang F and Zhang F, 2015. Formation of present desert landscape surrounding Jilantai Salt Lake in northern China based on OSL dating. Frontiers of Earth Science 9(3): 497-508, DOI: 10.1007/s11707-014-0482-3.

Fan YX, Wang YD, Mou XS, Zhao H, Zhang F, Zhang F, Liu WH, Hui ZC, Huang XZ and Ma J, 2017. Environmental status of the Jilantai Basin, North China, on the northwestern margin of the modern Asian summer monsoon domain during Marine Isotope Stage 3. Journal of Asian Earth Sciences 147: 178-192, DOI: 10.1016/j.jseaes.2017.07.012.

Guralnik B, Li B, Jain M, Chen R, Paris RB, Murray AS, Li SH, Pagonis V, Valla PG and Herman F, 2015. Radiation-induced growth and isothermal decay of infrared-stimulated luminescence from feldspar. Radiation Measurements 81: 224-231, DOI: 10.1016/j.radmeas.2015.02.011

Hu G, Yi CL, Zhang JF, Liu JH, Jiang T and Li SH, 2016. Late Quaternary glacial advances in the eastern Qilianshan, north-eastern Tibet, as inferred from luminescence dating of fluvioglacial sediments. Journal of Quaternary Science 31: 587-597, DOI: $10.1002 /$ jqs.2882.
Jia LY, Zhang XJ, He ZX, He XL, Wu FD, Zhou YQ, Fu LZ and Zhao JX, 2015. Late Quaternary climatic and tectonic mechanisms driving river terrace development in an area of mountain uplift: A case study in the Langshan area, Inner Mongolia, northern China. Geomorphology 234: 109-121, DOI: 10.1016/j.geomorph.2014.12.043.

Lai ZP, 2006. Testing the use of an OSL standardised growth curve (SGC) for $D_{e}$ determination on quartz from the Chinese Loess Plateau. Radiation Measurements 41(1): 9-16, DOI: 10.1016/j.radmeas.2005.06.031.

Lai ZP, Brückner H, Zöller L and Fülling A, 2007. Existence of a common growth curve for silt-sized quartz OSL of loess from different continents. Radiation Measurements 42(9): 14321440, DOI: 10.1016/j.radmeas.2007.08.006.

Lai ZP, 2010. Chronology and the upper dating limit for loess samples from Luochuan section in the Chinese Loess Plateau using quartz OSL SAR protocol. Journal of Asian Earth Sciences 37(2): 176-185, DOI: 10.1016/j.jseaes.2009.08.003.

Lai ZP and Ou XJ, 2013. Basic procedures of optically stimulated luminescence (OSL) dating. Progress in Geography 32(5): 683-693, DOI: 10.11820/dlkxjz.2013.05.001. (in Chinese with English abstract).

Li B, Roberts RG, Jacobs Z and Li SH, 2015. Potential of establishing a 'global standardised growth curve' (gSGC) for optical dating of quartz from sediments. Quaternary Geochronology 27: 94-104, DOI: 10.1016/j.quageo.2015.02.011.

Li B, Jacobs Z and Roberts RG, 2016. Investigation of the applicability of standardised growth curves for OSL dating of quartz from Haua Fteah cave, Libya. Quaternary Geochronology 35: 1-15, DOI: 10.1016/j.quageo.2016.05.001.

Li B, Jacobs Z, Roberts RG and Li SH, 2018. Single-grain dating of potassium-rich feldspar grains: Towards a global standardised growth curve for the post-IR IRSL signal. Quaternary Geochronology 45: 23-36, DOI: 10.1016/j.quageo.2018.02.001.

Long H, Lai ZP, Fan QS, Sun YJ and Liu XJ, 2010. Applicability of a quartz OSL standardised growth curve for $\mathrm{D}_{\mathrm{e}}$ determination up to $400 \mathrm{~Gy}$ for lacustrine sediments from the Qaidam Basin of the Qinghai-Tibetan Plateau. Quaternary Geochronology 5(2-3): 212-217, DOI: 10.1016/j.quageo.2009.05.005.

Murray AS and Wintle AG, 1999a. Isothermal decay of optically stimulated luminescence in quartz. Radiation Measurements 30(1): 119-125, DOI: 10.1016/S1350-4487(98)00097-3.

Murray AS and Wintle AG, 1999b. Sensitisation and Stability of Quartz OSL: Implications for Interpretation of Dose Response Curves. Radiation Protection Dosimetry 84(1): 427-432. DOI: 10.1093/oxfordjournals.rpd.a032770.

Peng J, Pagonis V, and Li B, 2016. On the intrinsic accuracy and precision of the standardised growth curve (SGC) and global-SGC (gSGC) methods for equivalent dose determination: A simulation study. Radiation Measurements 94: 53-64, DOI: 10.1016/j.radmeas.2016.09.006. 
Peng J and Li B, 2017. Single-aliquot regenerative-dose (SAR) and standardised growth curve (SGC) equivalent dose determination in a batch model using the R Package 'numOSL'. Ancient TL 35(2): 32-53.

Roberts HM and Duller GAT, 2004. Standardised growth curves for optical dating of sediment using multiple-grain aliquots. Radiation Measurements 38(2): 241-252, DOI: 10.1016/j.radmeas.2003.10.001.

Stevens T, Armitage SJ, Lu HY and Thomas DSG, 2007. Examining the potential of high sampling resolution OSL dating of Chinese loess. Quaternary Geochronology 2(1-4): 15-22, DOI: 10.1016/j.quageo.2006.03.004.

Telfer MW, Bateman MD, Carr AS and Chase BM, 2008. Testing the applicability of a standardized growth curve (SGC) for quartz OSL dating: Kalahari dunes, South African coastal dunes and Florida dune cordons. Quaternary
Geochronology 3(1-2): 137-142, DOI: 10.1016/j.quageo.2007.08.001.

Yang H, Zhao H, Wang X and Geng J, 2017. Optical Dating Equivalent Dose $\left(D_{e}\right)$ Comparison of Global Standardised Growth Curve (gSGC) and Single-aliquot Regenerative-dose (SAR) Methods for Quartz Grains. Advances in Earth Science 32(10): 1111-1118, DOI: 10. 11867/ j. issn. 1001-8166. 2017. 10. 1111. (in Chinese with English abstract).

Yang LH, Lai ZP, Long H and Zhang JR, 2011. Construction of a quartz OSL standardised growth curve (SGC) for aeolian samples from the Horqin dunefield in northeastern China. Geochronometria 38(4): 391-396, DOI: 10.2478/s13386-011-0045-2.

Zhao H, Li GQ, Sheng YW, Jin M and Chen FH, 2012. Early-middle Holocene lake-desert evolution in northern Ulan Buh Desert, China. Palaeogeography, Palaeoclimatology, Palaeoecology 331-332: 31-38, DOI: 10.1016/j.palaeo.2012.02.027. 


\title{
ESTABLISHING A COMMON STANDARDISED GROWTH CURVE FOR SINGLE-ALIQUOT OSL DATING OF QUARTZ FROM SEDIMENTS IN THE JILANTAI AREA OF NORTH CHINA
}

\author{
ZHENJUN LI ${ }^{1}$, XUESONG MOU ${ }^{1}$, YUXIN FAN $^{1 *}$, QINGSONG ZHANG ${ }^{1}$, GUANGLIANG YANG $^{1}$, HUI ZHAO $^{2}$ \\ ${ }^{1}$ Key Laboratory of Mineral Resources in Western China (Gansu Province), School of Earth Sciences, \\ Lanzhou University, China \\ ${ }^{2}$ North-west Institute of Eco-Environment and Resources, Chinese Academy of Science, Lanzhou 730000, China
}

\section{Supplementary Data}

\section{Supplementary tables}

Table S1. The double SAR protocol applied in measuring OSL signals in this study.

\begin{tabular}{llc}
\hline Step & Operation & Measured \\
\hline 1 & Regeneration dose di $(i=0,1,2,3,4,5)$ & $\mathrm{d} 0=0, \mathrm{~d} 1=\mathrm{d} 4$ \\
2 & Preheat $@ 160-260^{\circ} \mathrm{C}$ for $10 \mathrm{~s}$ & $\mathrm{Lx}$ \\
3 & OSL @ $50^{\circ} \mathrm{C}$ for $40 \mathrm{~s}$ & \\
4 & OSL @ $125^{\circ} \mathrm{C}$ for $40 \mathrm{~s}$ & \\
5 & Test dose $20-100 \mathrm{~s}$ & $\mathrm{Tx}$ \\
6 & $\mathrm{TL} 160-220^{\circ} \mathrm{C}$ & \\
7 & OSL @ $50^{\circ} \mathrm{C}$ for $40 \mathrm{~s}$ & \\
8 & OSL @ $125^{\circ} \mathrm{C}$ for $40 \mathrm{~s}$ & \\
9 & Illumination @ $280^{\circ} \mathrm{C}$ for $100 \mathrm{~s}$ & \\
\hline Note: A complete sequence in measurement of OSL signals of samples is usually \\
composed of 5-6 runs of operations from 1-9 with the only difference of regen- \\
eration dose.
\end{tabular}

Table S2. A summary of studied samples, including their locations, sedimentary types and grain size and measurement conditions in measuring OSL signals of quartz in this study.

\begin{tabular}{|c|c|c|c|c|c|c|c|c|}
\hline Profile/Core & Sample & Location & $\begin{array}{l}\text { Sediment } \\
\text { type }\end{array}$ & $\begin{array}{l}\text { Grain size } \\
\qquad(\mu \mathrm{m})\end{array}$ & $\begin{array}{c}\text { Preheat/cut- } \\
\text { heat }\left({ }^{\circ} \mathrm{C}\right)\end{array}$ & Test dose (s) & $\begin{array}{l}\text { Number of } \\
\text { aliquots }\end{array}$ & Data source \\
\hline \multirow{9}{*}{ DK12 } & DK-1 & \multirow{9}{*}{$\begin{array}{l}\mathrm{N} 40^{\circ} 23^{\prime} 14.3^{\prime \prime}, \\
\mathrm{E} 106^{\circ} 40^{\prime} 12.0^{\prime \prime}\end{array}$} & Lacustrine & $180-250$ & $200 / 160$ & 100 & 10 & \multirow{9}{*}{ (Fan et al., 2017) } \\
\hline & DK-2 & & Lacustrine & $180-250$ & $160 / 160$ & 100 & 11 & \\
\hline & DK-3 & & Lacustrine & $180-250$ & $180 / 160$ & 100 & 12 & \\
\hline & DK-4 & & Lacustrine & $180-250$ & $200 / 160$ & 100 & 11 & \\
\hline & DK-5 & & Lacustrine & $180-250$ & $220 / 160$ & 100 & 12 & \\
\hline & DK-6 & & Lacustrine & $180-250$ & $180 / 160$ & 100 & 12 & \\
\hline & DK-7 & & Lacustrine & $180-250$ & $260 / 160$ & 100 & 11 & \\
\hline & DK-1\# & & Lacustrine & $180-250$ & $200 / 160$ & 50 & 7 & \\
\hline & DK-2\# & & Lacustrine & $180-250$ & $160 / 160$ & 100 & 6 & \\
\hline
\end{tabular}




\begin{tabular}{|c|c|c|c|c|c|c|c|c|}
\hline Profile/Core & Sample & Location & $\begin{array}{l}\text { Sediment } \\
\text { type }\end{array}$ & $\begin{array}{l}\text { Grain size } \\
(\mu \mathrm{m})\end{array}$ & $\begin{array}{l}\text { Preheat/cut- } \\
\text { heat }\left({ }^{\circ} \mathrm{C}\right)\end{array}$ & Test dose (s) & $\begin{array}{l}\text { Number of } \\
\text { aliquots }\end{array}$ & Data source \\
\hline \multirow{8}{*}{ LS } & LS-1 & \multirow{8}{*}{$\begin{array}{l}\text { N40 } 26^{\prime} 22.88^{\prime \prime}, \\
\text { E106 } 11^{\prime} 36.26^{\prime \prime}\end{array}$} & Lacustrine & $90-125$ & $160 / 160$ & 30 & 8 & \multirow{8}{*}{ (Zhang 2016) } \\
\hline & LS-2 & & Lacustrine & $90-125$ & $180 / 160$ & 30 & 5 & \\
\hline & LS-3 & & Lacustrine & $90-125$ & 200/160 & 30 & 12 & \\
\hline & LS-4 & & Lacustrine & $90-125$ & $260 / 160$ & 30 & 11 & \\
\hline & LS-1\# & & Lacustrine & $90-125$ & $160 / 160$ & 30 & 12 & \\
\hline & LS-2\# & & Lacustrine & $90-125$ & $180 / 160$ & 30 & 10 & \\
\hline & LS-3\# & & Lacustrine & $90-125$ & $200 / 160$ & 30 & 10 & \\
\hline & LS-4\# & & Lacustrine & $90-125$ & $260 / 160$ & 30 & 11 & \\
\hline \multirow{2}{*}{ S32 } & S32-1 & \multirow{2}{*}{ 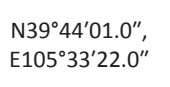 } & Lacustrine & $90-125$ & $160 / 160$ & 30 & 8 & \multirow{2}{*}{ (Zhang 2016) } \\
\hline & S32-2 & & Lacustrine & $90-125$ & $260 / 160$ & 30 & 10 & \\
\hline \multirow{3}{*}{ S40 } & $S 40-1$ & \multirow{3}{*}{$\begin{array}{l}\text { N39 } 56^{\prime} 55.10^{\prime \prime}, \\
\text { E105 } 38^{\prime} 07.50^{\prime \prime}\end{array}$} & Lacustrine & $90-125$ & 200/160 & 50 & 16 & \multirow{3}{*}{ (Zhang 2015) } \\
\hline & $540-2$ & & Lacustrine & $90-125$ & $180 / 160$ & 50 & 11 & \\
\hline & $540-3$ & & Lacustrine & $90-125$ & $260 / 160$ & 50 & 10 & \\
\hline \multirow{3}{*}{ S42 } & S42-1 & \multirow{3}{*}{$\begin{array}{l}\text { N39 } 56^{\circ} 54.58^{\prime \prime}, \\
\text { E105 } 37^{\prime} 5.51^{\prime \prime}\end{array}$} & Lacustrine & $90-125$ & $180 / 160$ & 50 & 9 & \multirow{3}{*}{ (Zhang 2015) } \\
\hline & $S 42-2$ & & Lacustrine & $90-125$ & $240 / 160$ & 50 & 8 & \\
\hline & $542-3$ & & Lacustrine & $90-125$ & $180 / 160$ & 50 & 12 & \\
\hline \multirow{4}{*}{563} & s63-1 & \multirow{4}{*}{ 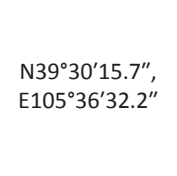 } & Lacustrine & $90-125$ & $200 / 160$ & 50 & 10 & \multirow{4}{*}{ This work } \\
\hline & s63-2 & & Lacustrine & $90-125$ & $220 / 160$ & 50 & 4 & \\
\hline & S63-3 & & Lacustrine & $90-125$ & $160 / 160$ & 50 & 8 & \\
\hline & S63-2\# & & Lacustrine & $90-125$ & $220 / 160$ & 50 & 11 & \\
\hline \multirow{2}{*}{ WP130725 } & WP130725-1 & \multirow{2}{*}{$\begin{array}{l}\text { N39 } 10^{\prime} 56.64^{\prime \prime}, \\
\text { E105 } 39^{\prime} 38.92^{\prime \prime}\end{array}$} & Fluvial & $90-125$ & $160 / 160$ & 50 & 14 & \multirow{2}{*}{ (Zhang 2015) } \\
\hline & WP130725-2 & & Fluvial & $90-125$ & $160 / 160$ & 50 & 6 & \\
\hline \multirow{3}{*}{ WP130726-2 } & WP130726-2-1 & \multirow{3}{*}{$\begin{array}{l}\text { N39 } 27^{\prime} 57.68^{\prime \prime} \\
\text { E105'38'17.24" }\end{array}$} & Fluvial & $90-125$ & $180 / 160$ & 50 & 11 & \multirow{3}{*}{ This work } \\
\hline & WP130726-2-2 & & Fluvial & $90-125$ & $160 / 160$ & 50 & 11 & \\
\hline & WP130726-2-3 & & Fluvial & $90-125$ & $220 / 160$ & 50 & 11 & \\
\hline \multirow{2}{*}{ WP130726-3 } & WP130726-3-1 & \multirow{2}{*}{$\begin{array}{l}\text { N39 } 27^{\prime} 3.79^{\prime \prime}, \\
\text { E105'39'5.79" }\end{array}$} & Fluvial & $90-125$ & $240 / 160$ & 50 & 9 & This work \\
\hline & WP130726-3-2 & & Fluvial & $90-125$ & $220 / 160$ & 50 & 12 & 17is work \\
\hline WP130729 & WP130729-1 & N39 $20^{\prime} 50.5^{\prime \prime}$, & Fluvial & $90-125$ & $240 / 160$ & 50 & 16 & (Zhang 2015) \\
\hline & WP130729-2 & E105'41'52.7" & Fluvial & $90-125$ & $180 / 160$ & 50 & 12 & \\
\hline S39 & s39-1 & N39 $58^{\prime} 32^{\prime \prime}$ & Lacustrine & $106-180$ & $260 / 220$ & 80 & 15 & (Fan 2008) \\
\hline & S39-2 & E105 $37^{\prime} 07^{\prime \prime}$ & Lacustrine & $150-180$ & $260 / 220$ & 80 & 12 & \\
\hline S27 & S27-1 & $\begin{array}{l}\text { N39 } 34^{\prime} 14^{\prime \prime}, \\
\text { E105 } 35^{\prime} 37^{\prime \prime}\end{array}$ & Lacustrine & $90-125$ & $260 / 160$ & 100 & 6 & (Fan 2008) \\
\hline S22 & S22-1 & $\begin{array}{l}\text { N39 } 59^{\circ} 14^{\prime \prime} \\
\text { E105 } 39^{\prime} 45^{\prime \prime}\end{array}$ & Lacustrine & $90-125$ & $260 / 160$ & 50 & 13 & (Fan 2008) \\
\hline S18 & S18-1 & $\begin{array}{l}\text { N39 } 47^{\prime} 53^{\prime \prime}, \\
\text { E105 } 39^{\prime} 58^{\prime \prime}\end{array}$ & Lacustrine & $90-125$ & $260 / 220$ & 50 & 22 & (Fan 2008) \\
\hline & S21-1 & & Lacustrine & $180-300$ & $260 / 160$ & 50 & 15 & \\
\hline S21 & S21-2 & $\begin{array}{l}\mathrm{N} 39^{\circ} 47^{\prime} 01^{\prime \prime}, \\
\mathrm{E} 105^{\circ} 39^{\prime} 24^{\prime \prime}\end{array}$ & Lacustrine & $90-125$ & $260 / 160$ & 20 & 16 & (Fan 2008) \\
\hline & S21-3 & & Lacustrine & $300-500$ & $260 / 160$ & 80 & 11 & \\
\hline S37 & S37-1 & $\begin{array}{l}\text { N39 } 49^{\circ} 45^{\prime \prime}, \\
\text { E105 } 39^{\prime} 34^{\prime \prime}\end{array}$ & Lacustrine & $125-180$ & $260 / 160$ & 20 & 12 & (Fan 2008) \\
\hline S16 & S16-1 & N39 $44^{\prime} 11^{\prime \prime}$, & Lacustrine & $90-125$ & $260 / 160$ & 50 & 6 & (Fan 2008) \\
\hline & S16-2 & $\mathrm{E} 105^{\circ} 34^{\prime} 24^{\prime \prime}$ & Lacustrine & $250-300$ & $260 / 220$ & 50 & 29 & \\
\hline S11 & S11-1 & N39 $44^{\prime} 57^{\prime \prime}$, & Lacustrine & $180-300$ & $260 / 160$ & 20 & 16 & (Fan 2008) \\
\hline & S11-2 & $\mathrm{E} 105^{\circ} 38^{\prime} 40^{\prime \prime}$ & Lacustrine & $90-125$ & $260 / 220$ & 20 & 28 & \\
\hline 548 & S48-1 & $\begin{array}{l}\text { N39 } 49^{\circ} 03^{\prime \prime}, \\
\text { E105 } 34^{\prime} 24^{\prime \prime}\end{array}$ & Lacustrine & $250-300$ & $260 / 160$ & 20 & 18 & (Fan 2008) \\
\hline
\end{tabular}




\begin{tabular}{|c|c|c|c|c|c|c|c|c|}
\hline Profile/Core & Sample & Location & $\begin{array}{c}\text { Sediment } \\
\text { type }\end{array}$ & $\begin{array}{c}\text { Grain size } \\
(\mu \mathrm{m})\end{array}$ & $\begin{array}{c}\text { Preheat/cut- } \\
\text { heat }\left({ }^{\circ} \mathrm{C}\right)\end{array}$ & Test dose (s) & $\begin{array}{c}\text { Number of } \\
\text { aliquots }\end{array}$ & Data source \\
\hline S41 & S41-1 & $\begin{array}{l}\mathrm{N} 39^{\circ} 58^{\prime} 12^{\prime \prime}, \\
\mathrm{E} 105^{\circ} 38^{\prime} 29^{\prime \prime}\end{array}$ & Lacustrine & $500-1000$ & $260 / 220$ & 50 & 7 & (Fan 2008) \\
\hline BS6 & BS6-1 & $\begin{array}{l}\text { N39 } 39^{\circ} 9^{\prime} 39^{\prime \prime}, \\
\text { E105 } 40^{\prime} 54^{\prime \prime}\end{array}$ & Dune & $90-125$ & $260 / 160$ & 20 & 9 & (Fan et al., 2010) \\
\hline \multirow{4}{*}{ S7 } & S7-1 & & Dune & $90-125$ & $260 / 160$ & 20 & 9 & \multirow{4}{*}{ (Fan et al., 2010) } \\
\hline & $S 7-2$ & N39 $39^{\prime} 53^{\prime \prime}$ & Dune & $125-150$ & $260 / 220$ & 80 & 13 & \\
\hline & S7-3 & $\mathrm{E} 105^{\circ} 36^{\prime} 17^{\prime \prime}$ & Dune & $125-150$ & $260 / 220$ & 50 & 6 & \\
\hline & S7-4 & & Dune & $250-300$ & $260 / 160$ & 20 & 8 & \\
\hline WLD07A & WLD07A-1 & $\begin{array}{l}\mathrm{N} 39^{\circ} 46^{\prime} 03^{\prime \prime}, \\
\mathrm{E} 105^{\circ} 45^{\prime} 38^{\prime \prime}\end{array}$ & Dune & $125-180$ & $260 / 220$ & 50 & 5 & (Fan et al., 2010) \\
\hline WLD07B & WLD07B-1 & $\begin{array}{l}\text { N39 } 50^{\circ} 1^{\prime} 41^{\prime \prime}, \\
\text { E106 } 23^{\prime} 20^{\prime \prime}\end{array}$ & Dune & $125-180$ & $260 / 220$ & 50 & 19 & (Fan et al., 2010) \\
\hline WLD07D & WLD07D-1 & $\begin{array}{l}\text { N39 } 59^{\circ} 03^{\prime \prime}, \\
\text { E105 } 49^{\prime} 54^{\prime \prime}\end{array}$ & Dune & $125-180$ & $260 / 220$ & 50 & 8 & (Fan et al., 2010) \\
\hline W7 & W7-1 & $\begin{array}{l}\text { N39 } 54^{\prime} 23^{\prime \prime}, \\
\text { E106 } 30^{\prime} 28^{\prime \prime}\end{array}$ & Dune & $90-125$ & $260 / 160$ & 20 & 7 & (Fan et al., 2010) \\
\hline
\end{tabular}

\section{Supplementary figures}

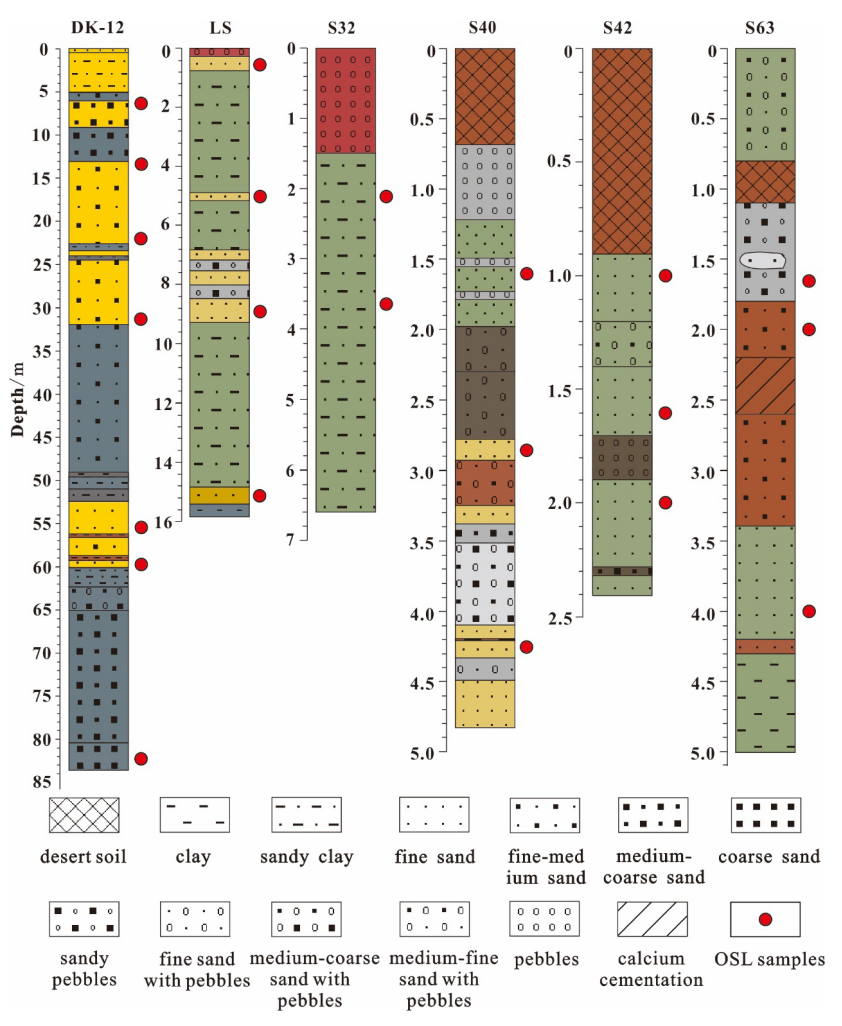

Figure S1. Lacustrine sedimentary profiles.

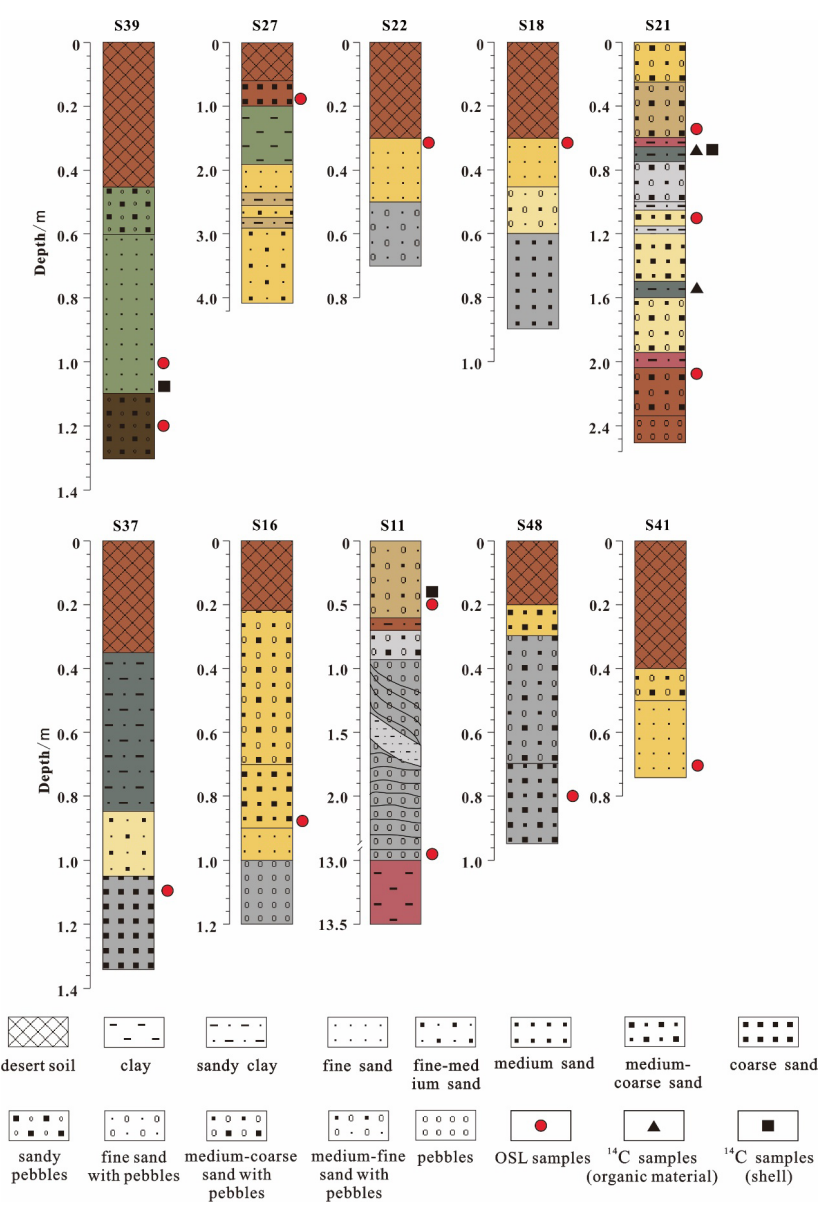

Figure S2. Lake shoreline profiles of the Jilantai Salt Lake. 

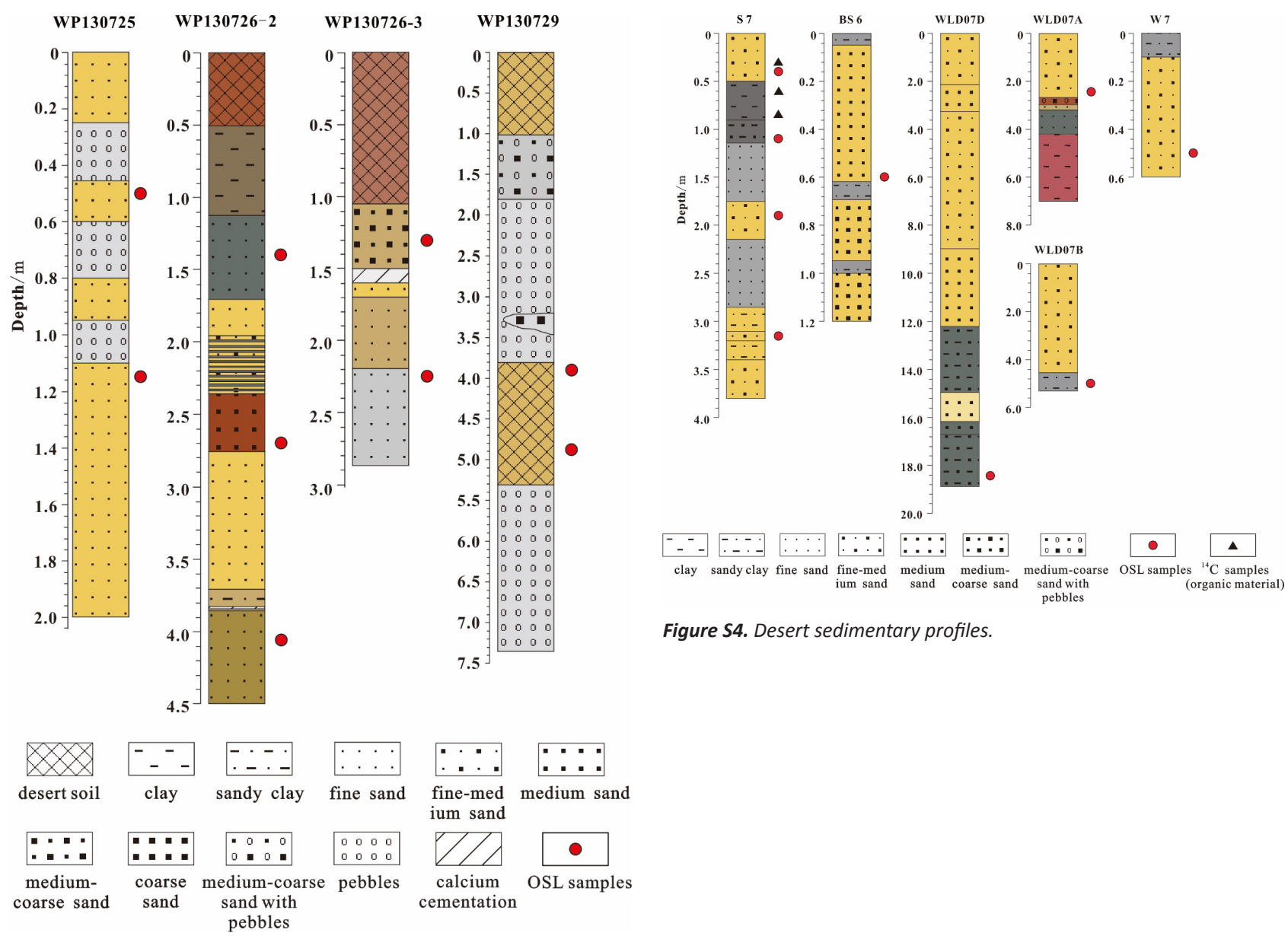

Figure S4. Desert sedimentary profiles.

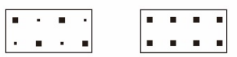

fine-med medium sand ium sand

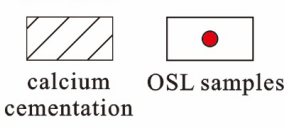

Figure S3. Fluvial sediment profiles.

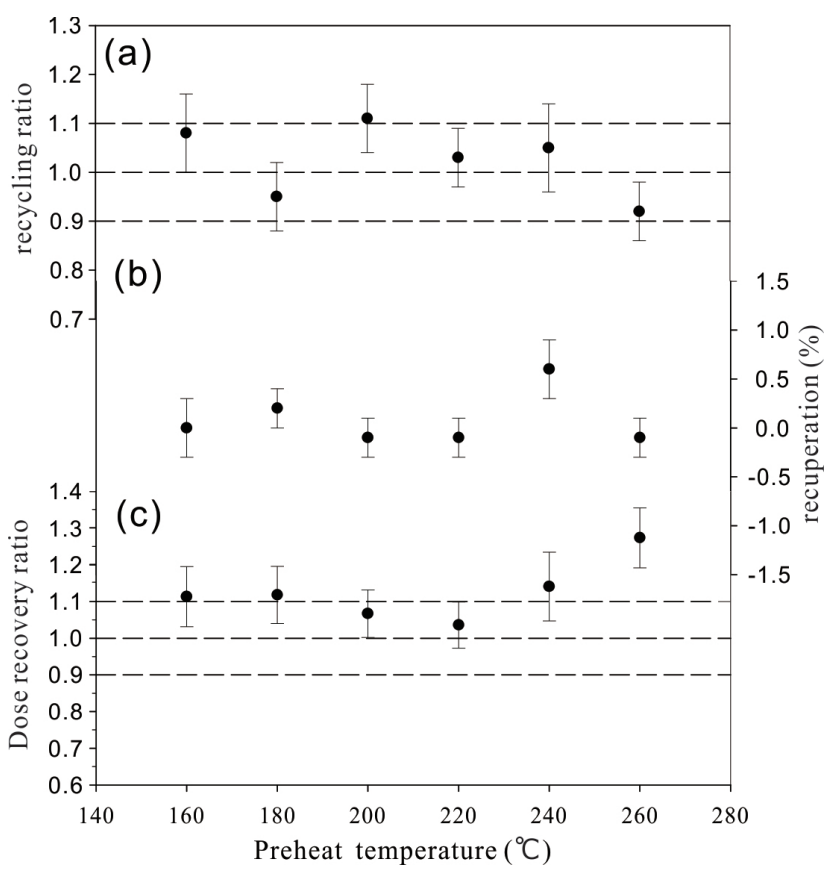

Figure S5. Results of a dose recovery test for a representative sample S63-2. 

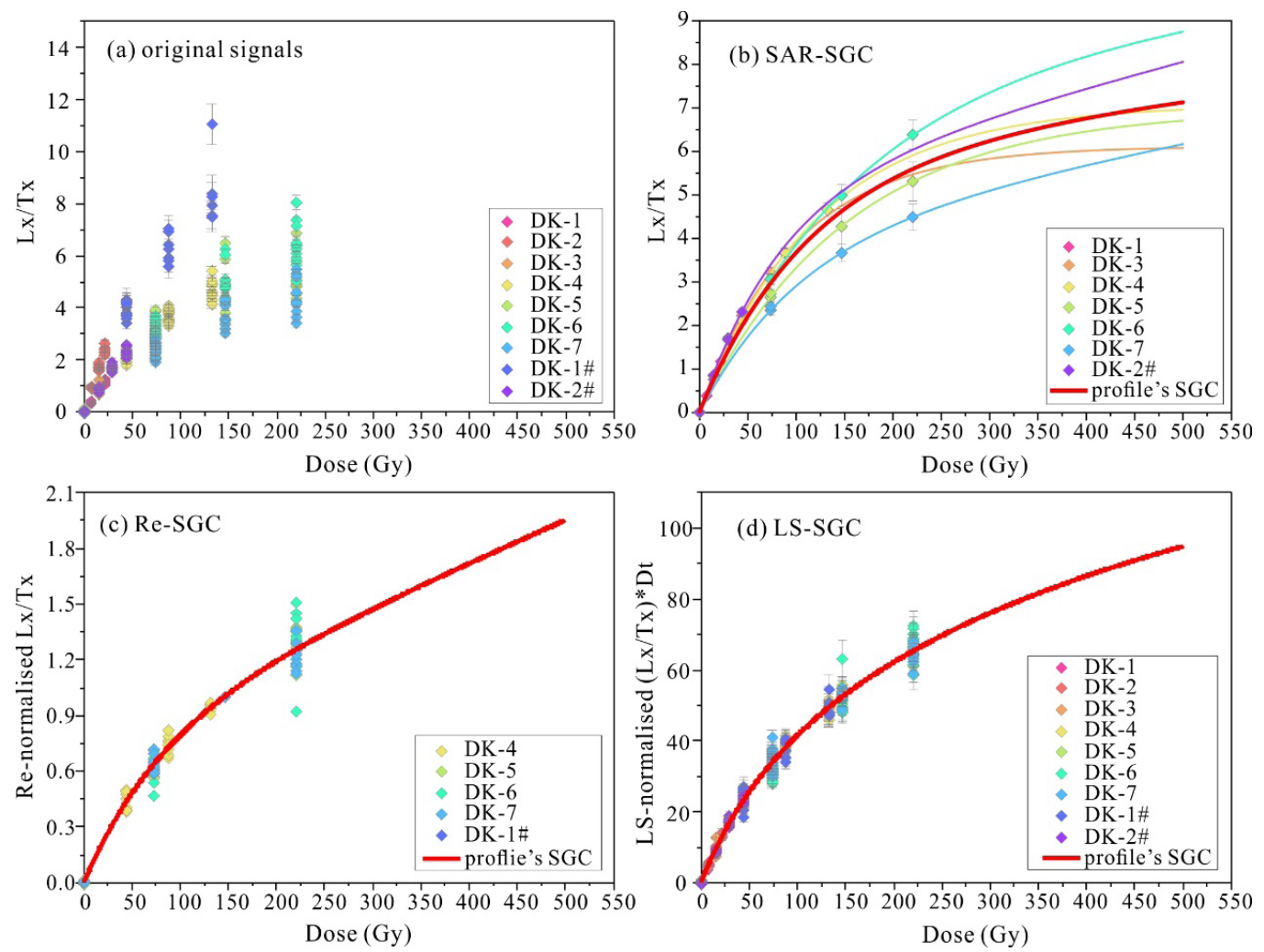

Figure S6. Comparison of SGCS for core DK12 established using three methods.
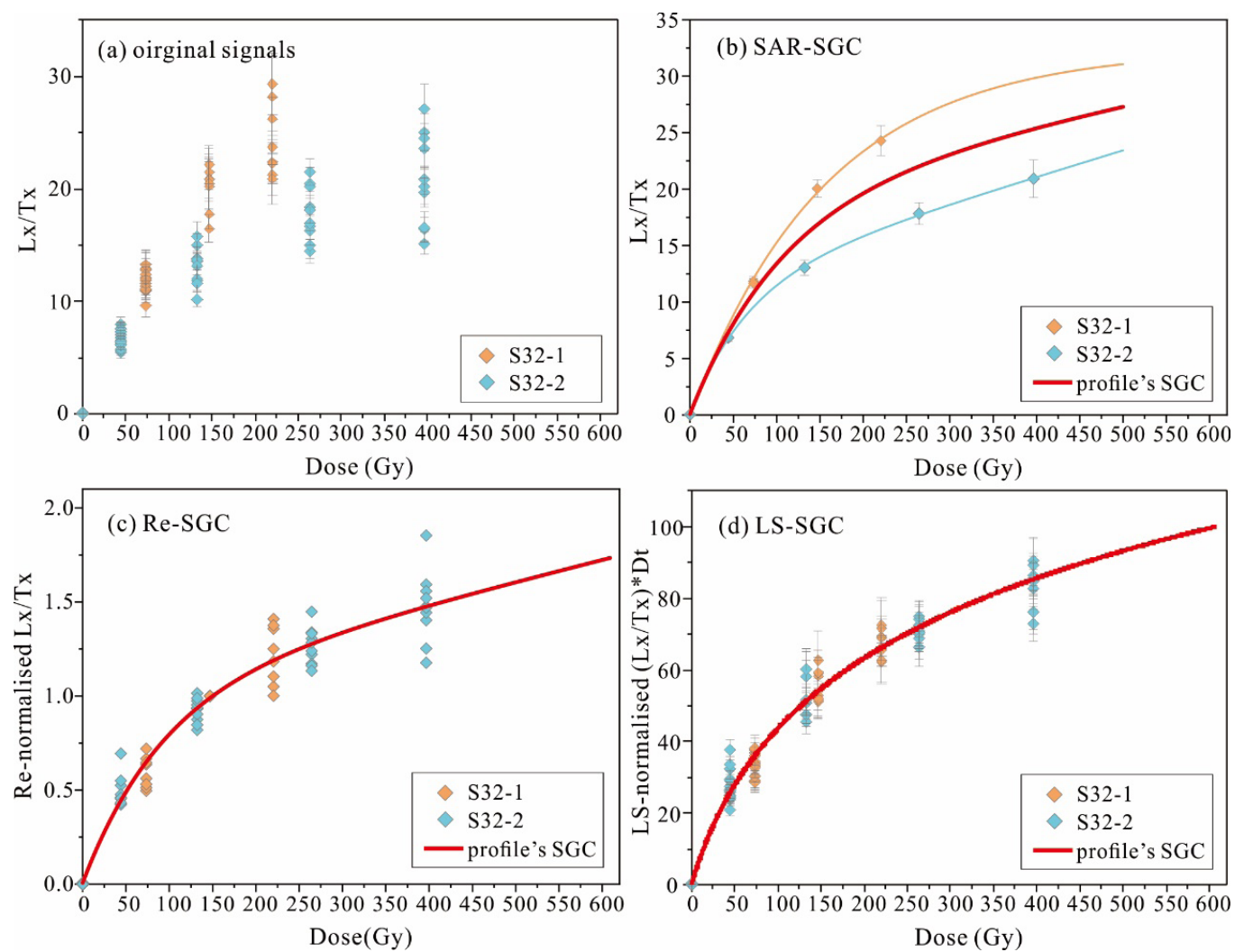

Figure S7. Comparison of SGCS for profile S32 established using three methods. 

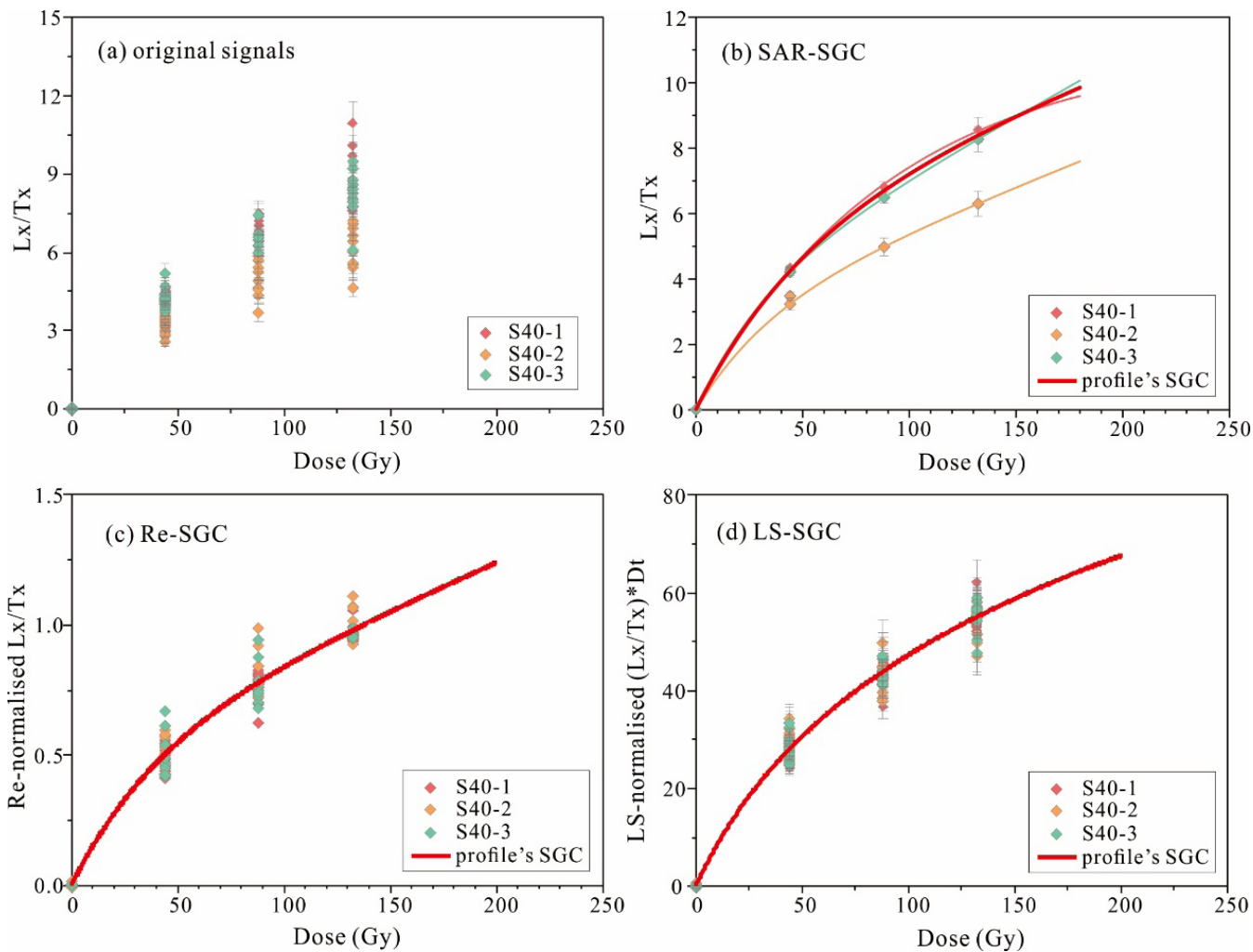

Figure S8. Comparison of SGCS for profile 540 established using three methods.
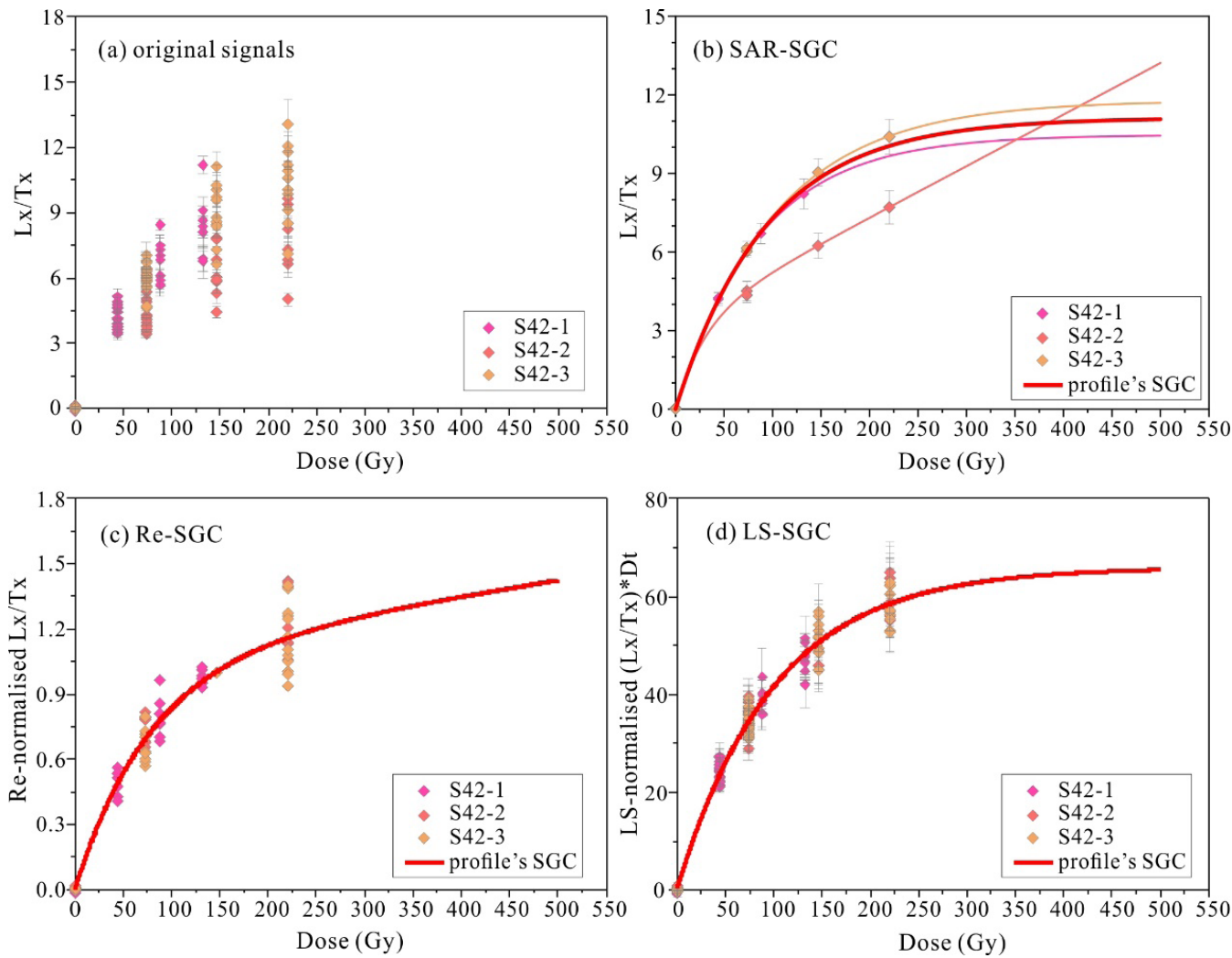

Figure 59. Comparison of SGCS for profile 542 established using three methods. 

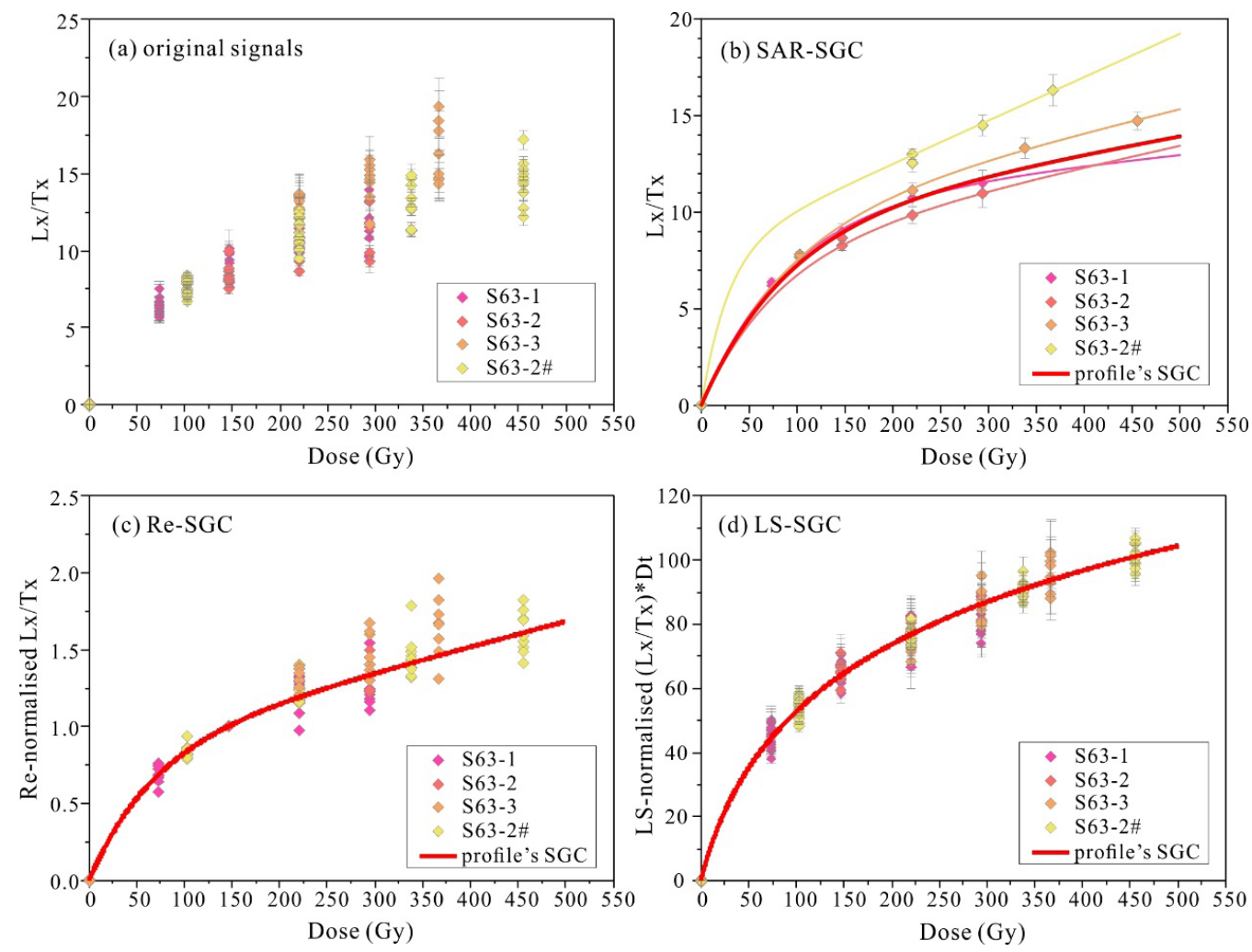

Figure S10. Comparison of SGCS for profile S63 profile established using three methods.
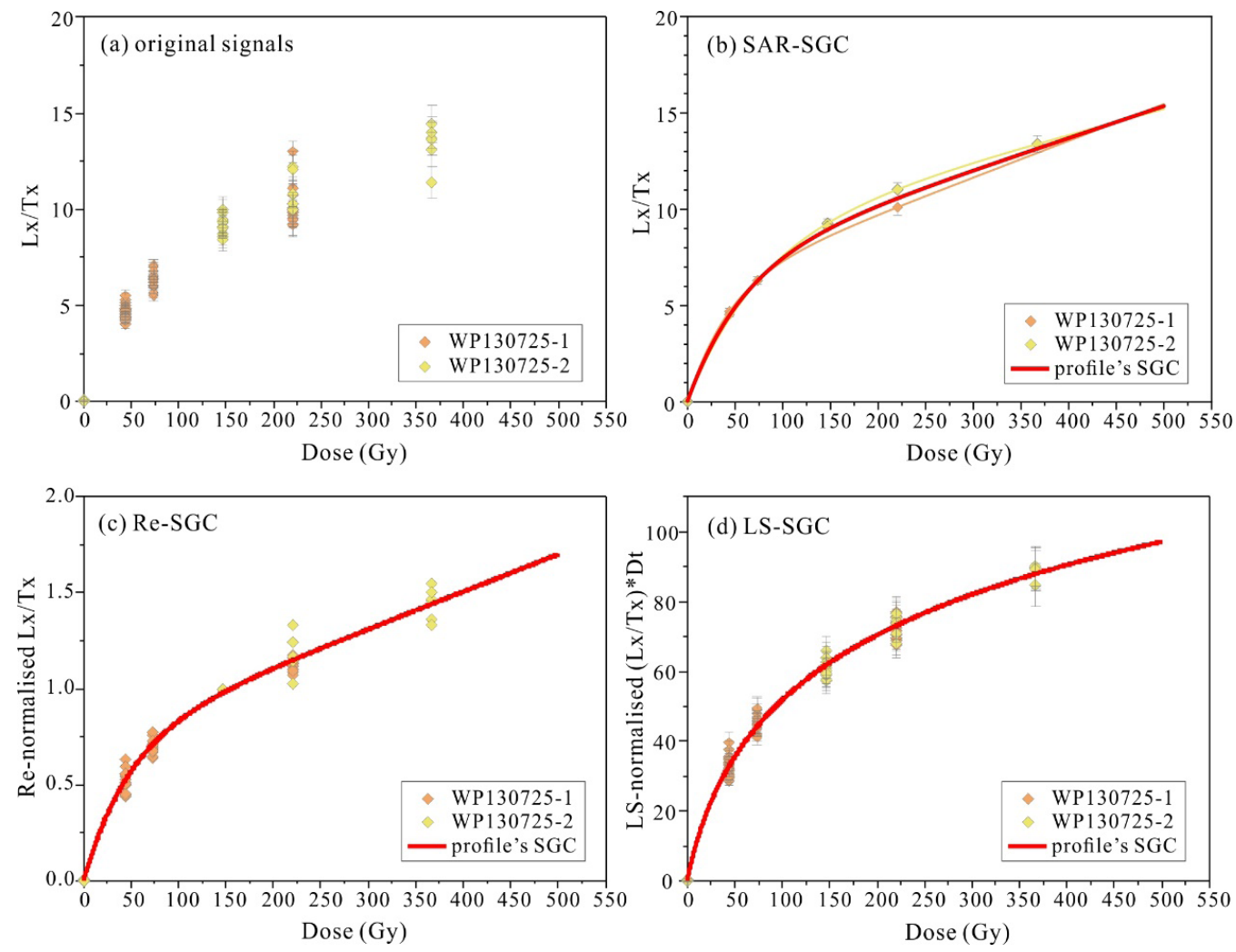

Figure S11. Comparison of SGCS for profile WP130725 established using three methods. 

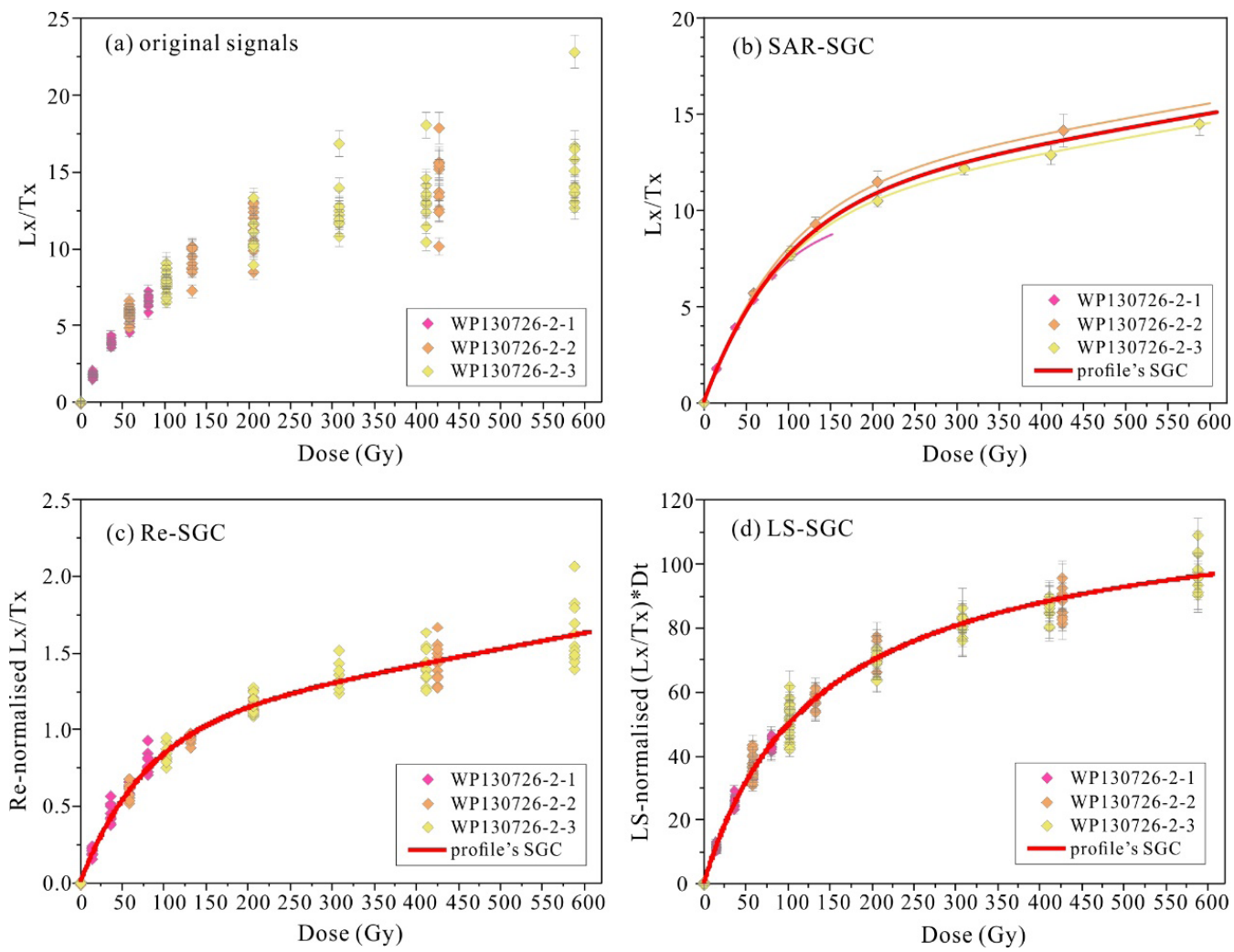

Figure S12. Comparison of SGCS for profile WP130726-2 established using three methods.
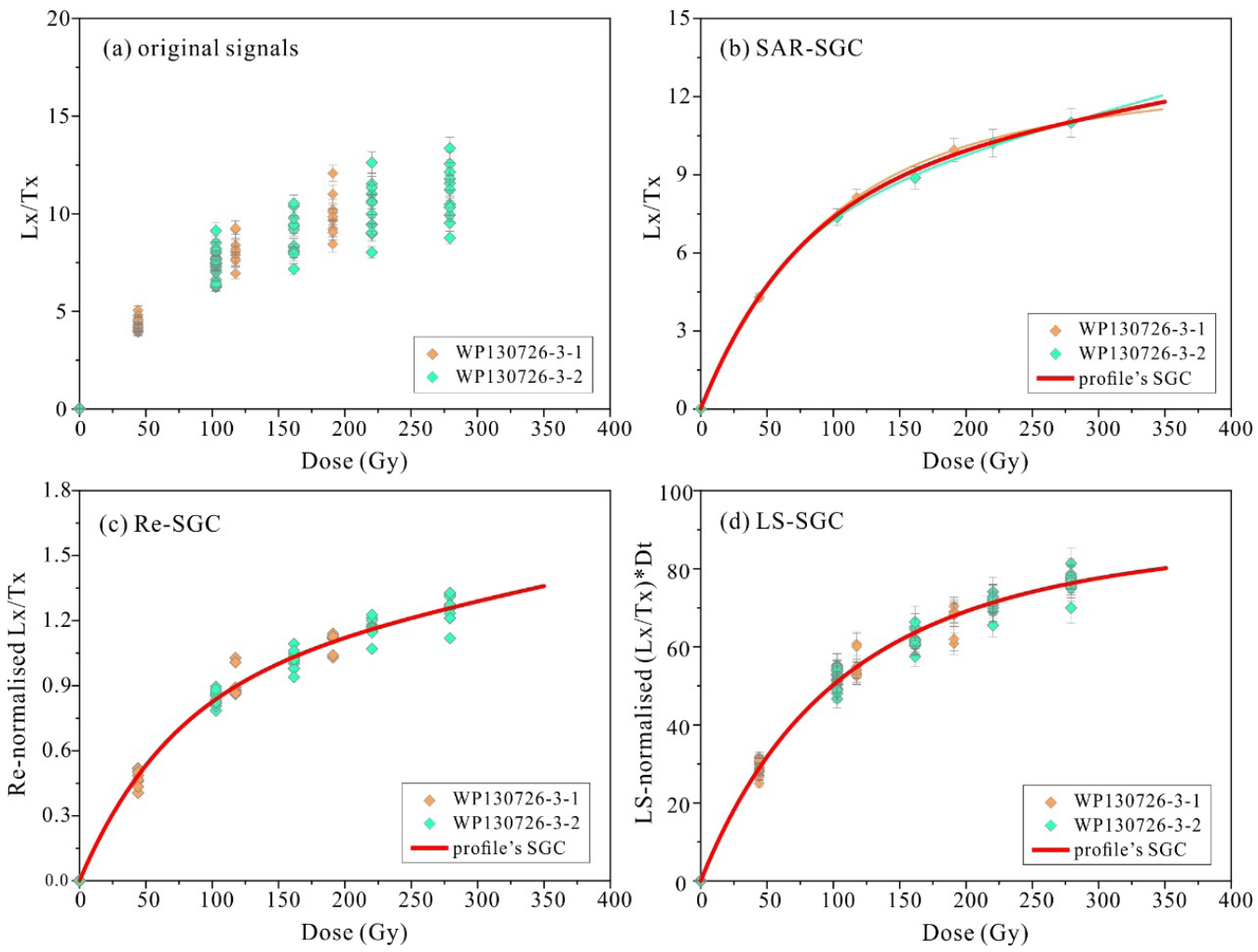

Figure S13. Comparison of SGCs for profile WP130726-3 established using three methods. 

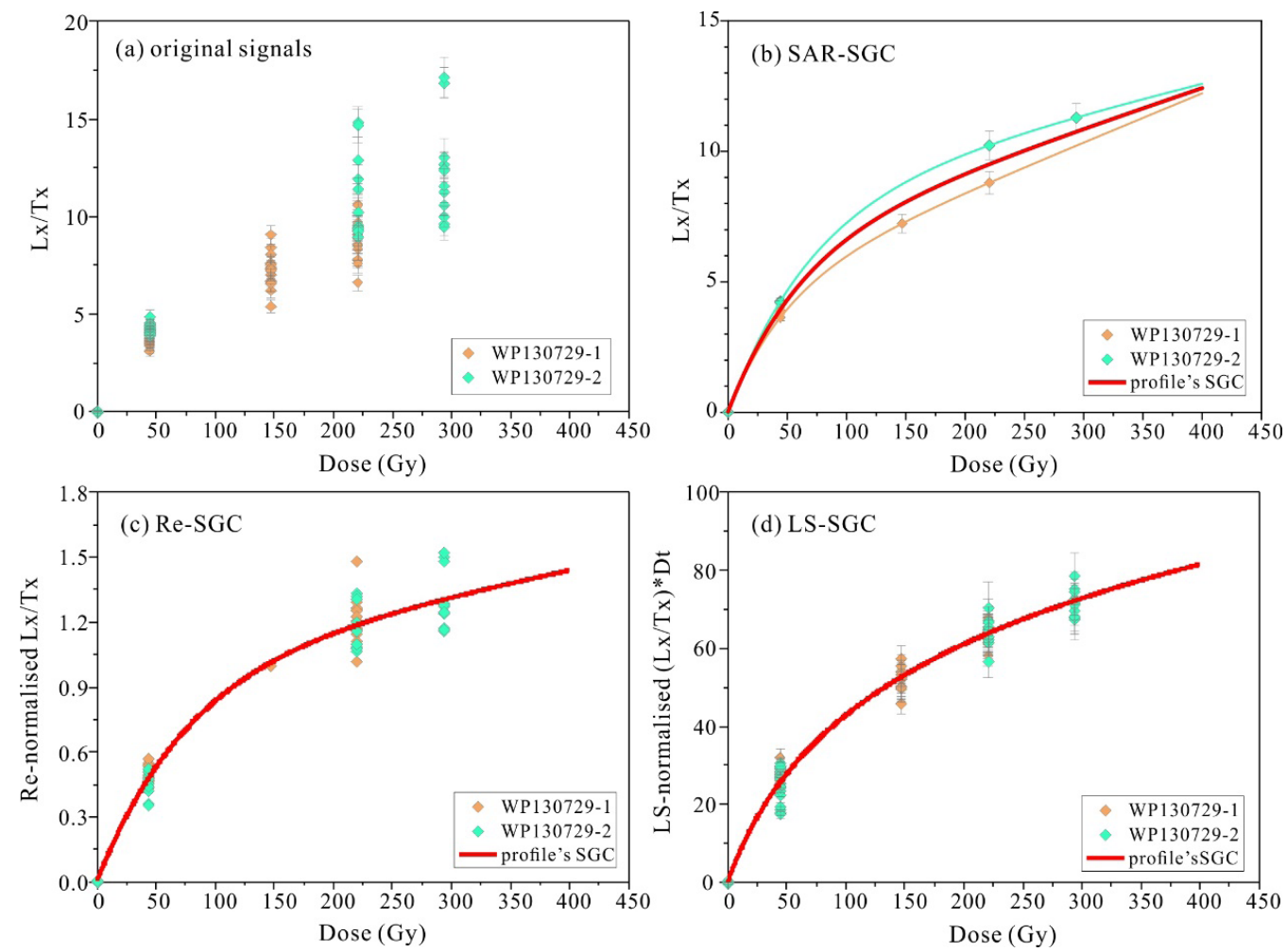

Figure S14. Comparison of SGCs for profile WP130729 established using three methods.

\section{Main references}

Fan YX, 2008. A study on the evolution of the Jilantai-Hetao Megalake: focusing on optical dating of lakeshore sediments. Lanzhou, Lanzhou University, PhD dissertation.

Fan YX, Chen FH, Fan TL, Zhao H and Yang LP, 2010. Sedimentary and Optically Stimulated Luminescence (OSL) dating for formation of the present northern Ulan Buh Desert landform in northern China. Science China Earth Sciences 53 (11): 1675-1682.

Fan YX, Wang YD, Mou XS, Zhao H, Zhang F, Zhang F, Liu WH, Hui ZC, Huang XZ and Ma J, 2017. Environmental status of the Jilantai Basin, North China, on the northwestern mar- gin of the modern Asian summer monsoon domain during Marine Isotope Stage 3. Journal of Asian Earth Sciences 147 (2017): 178-192.

Zhang F, 2015. The sedimentary and ecological environment research of Jilantai Basin during the MIS 3. Lanzhou, Lanzhou University, Master degree dissertation.

Zhang F, 2016. New findings of lacustrine sediments at southeastern piedmont of the Langshan Mountain and its implication for environmental status of the Jilantai Basin in Middle-Late Pleistocene: focusing on evidence of quartz OSL dating. Lanzhou, Lanzhou University, Master degree dissertation. 